August 2003

\title{
Psychosocial Development in Racially and Ethnically Diverse Youth: Conceptual and Methodological Challenges in the 21st Century
}

\author{
Dena Phillips Swanson \\ University of Pennsylvania \\ Margaret Beale Spencer \\ University of Pennsylvania, marges@gse.upenn.edu \\ Vinay Harpalani \\ University of Pennsylvania \\ Davido Dupree \\ University of Pennsylvania \\ Elizabeth Noll \\ University of Pennsylvania
}

See next page for additional authors

Follow this and additional works at: https://repository.upenn.edu/gse_pubs

\section{Recommended Citation}

Swanson, D. P., Spencer, M. B., Harpalani, V., Dupree, D., Noll, E., Ginzburg, S., \& Seaton, G. (2003).

Psychosocial Development in Racially and Ethnically Diverse Youth: Conceptual and Methodological Challenges in the 21st Century. Retrieved from https://repository.upenn.edu/gse_pubs/2

Copyright Cambridge University Press. Reprinted from Development and Psychopathology, Volume 15, Issue 3, August 2003, pages 743-771.

This paper is posted at ScholarlyCommons. https://repository.upenn.edu/gse_pubs/2

For more information, please contact repository@pobox.upenn.edu. 


\title{
Psychosocial Development in Racially and Ethnically Diverse Youth: Conceptual and Methodological Challenges in the 21st Century
}

\author{
Abstract \\ As the US population becomes more diverse in the 21 st century, researchers face many conceptual and \\ methodological challenges in working with diverse populations. We discuss these issues for racially and \\ ethnically diverse youth, using Spencer's phenomenological variant of ecological systems theory (PVEST) \\ as a guiding framework. We present a brief historical background and discuss recurring conceptual flaws \\ in research on diverse youth, presenting PVEST as a corrective to these flaws. We highlight the interaction \\ of race, culture, socioeconomic status, and various contexts of development with identity formation and \\ other salient developmental processes. Challenges in research design and interpretation of data are also \\ covered with regard to both assessment of contexts and developmental processes. We draw upon \\ examples from neighborhood assessments, ethnic identity development, and attachment research to \\ illustrate conceptual and methodological challenges, and we discuss strategies to address these \\ challenges. The policy implications of our analysis are also considered.

\section{Comments} \\ Copyright Cambridge University Press. Reprinted from Development and Psychopathology, Volume 15, \\ Issue 3, August 2003, pages 743-771.

\section{Author(s)} \\ Dena Phillips Swanson, Margaret Beale Spencer, Vinay Harpalani, Davido Dupree, Elizabeth Noll, Sofia \\ Ginzburg, and Gregory Seaton
}




\title{
Psychosocial development in racially and ethnically diverse youth: Conceptual and methodological challenges in the 21 st century
}

\author{
DENA PHILLIPS SWANSON, MARGARET BEALE SPENCER, \\ VINAY HARPALANI, DAVIDO DUPREE, ELIZABETH NOLL, \\ SOFIA GINZBURG, AND GREGORY SEATON \\ University of Pennsylvania
}

\begin{abstract}
As the US population becomes more diverse in the 21 st century, researchers face many conceptual and methodological challenges in working with diverse populations. We discuss these issues for racially and ethnically diverse youth, using Spencer's phenomenological variant of ecological systems theory (PVEST) as a guiding framework. We present a brief historical background and discuss recurring conceptual flaws in research on diverse youth, presenting PVEST as a corrective to these flaws. We highlight the interaction of race, culture, socioeconomic status, and various contexts of development with identity formation and other salient developmental processes. Challenges in research design and interpretation of data are also covered with regard to both assessment of contexts and developmental processes. We draw upon examples from neighborhood assessments, ethnic identity development, and attachment research to illustrate conceptual and methodological challenges, and we discuss strategies to address these challenges. The policy implications of our analysis are also considered.
\end{abstract}

As America moves into the 21st century, its population is changing rapidly and dramatically. According to demographic projections, by the year 2050, people of color will comprise close to $50 \%$ of the US population (Day, 1996). Many urban areas, particularly settings with low economic resources, already comprise a people of color majority. As this demographic trend continues in the United States, changes will be necessary in the delivery of mental health and social services. Assumptions

Support for the writing of this manuscript was made possible by grants to the second author from the NIMH, NSF, and the Kellogg and Ford Foundations.

Address correspondence and reprint requests to: Margaret Beale Spencer, CHANGES, University of Pennsylvania, 3440 Market Street, Suite 500, Philadelphia, PA 19104; E-mail: marges@gse.upenn.edu. regarding the pathology of non-White groups will be challenged and reevaluated more frequently, and social and psychological service organizations and service providers will have to adjust accordingly. Also, in order to effectively address the pertinent issues, the racialized privileges afforded to the current White majority in American society, such as a priori suppositions of normality, must be dismantled.

In this paper, we discuss several conceptual and methodological challenges facing researchers who wish to move beyond these recurrent errors to develop a more comprehensive understanding of psychological development for diverse youth. First, we also present a brief historical overview to contextualize research on diverse youth. We then review the conceptual flaws that have characterized scholarship on youth of color and propose general correc- 
tive perspectives to mitigate these flaws. Subsequently, we present Spencer's (1995) phenomenological variant of ecological systems theory (PVEST) as an overarching framework for research design and conceptual analysis across the life span. Next, we discuss conceptual and methodological challenges in studying context, identity development, and diversity. For our discussion of context, we incorporate tangible examples from our work in measuring neighborhood effects on youth development. To illustrate challenges in the assessment of developmental processes, we use examples from a variety of salient developmental phenomena, including attachment and identity formation (particularly racial/ethnic identity formation). Challenges related to research design and interpretation are also considered. In the next section, we address the policy implications of our inquiry. Finally, our conclusion recaps the research and policy implications of our work and raises further issues for exploration. Throughout the paper, PVEST is used as a guiding framework.

Although we highlight many examples for youth of color and particularly African American youth, our agenda entails youth of all race/ ethnic groups. "Diverse" also includes White; if it did not, this would only contribute to the normalization of "whiteness." White youth, like all others, must be studied as one of many diverse groups. The fact is that, whereas youth of color are disproportionately represented among the low economic resource population, many White youth are also in this group. Thus, the stresses faced by all of these youth may be similar, although low-income Whites typically have greater access to financial resources (through family connections, etc.) than people of color (Conley, 1999). In addition, White youth and youth of color face the same basic developmental challenges. The primary difference between the two is that White youth are considered to be the "norm" and reap all of the privileges of this status, ranging from greater cultural consonance across school, family, and neighborhood settings to "racial invisibility" in everyday encounters. Nonetheless, because the challenges faced by all "diverse" youth, generally, and youth of color, more specifically, overlap to an extent, we will have to be nuanced in our use of terminology. Thus, we will differentially refer to "youth of color" (designating all non-White youth), "low economic resource youth" (designating those of all race/ethnic backgrounds whose family incomes meet or approximate federal poverty guidelines), or all diverse youth, depending on the specific developmental issues and challenges being discussed. We should also note that the term diverse can be applied across a number of domains, including sexual orientation, special needs, etc. Given our particular focus and the space limitations of this paper, we will use the term diverse specifically to refer to racial and ethnic diversity, which, as we noted includes White youth. At times, we also refer to specific racial/ethnic groups, particularly African Americans, to illustrate challenges.

\section{Race and Ethnicity in America: A Brief Historical Overview}

Race has probably been the most salient and widely noted political issue in American history. Yet, commentators in the news media and in academia often neglect the general historical circumstances that brought about the current racial/ethnic composition and demographic trajectory of the United States. These circumstances provide the broader social and historical context for the everyday experiences of all Americans and thus lay part of the foundation for understanding the psychosocial development of diverse youth.

The work of John Ogbu presents a historical foundation for understanding the social and political positions of various racial/ethnic groups in America. Ogbu (1978, 1985, 1990) employs a framework to classify American minorities into three groups. Autonomous minorities are minorities primarily in numerical sense; although they are generally established populations in the United States, they may continue to face forms of discrimination (e.g., Jews, Mormons). Immigrant minorities are those who have come to the United States voluntarily with expectations of upward social mobility; the recent waves of Asian immigration provide an example. Finally, subordinate or castelike minorities have been incorporated involuntarily 
by the majority group through slavery or subjugation (e.g., Blacks, Native Americans).

Ogbu's framework provides us with a general understanding of the historical relationship that different groups have with this country. However, in other work, Ogbu (Fordham \& Ogbu, 1986) makes the mistake of drawing direct psychological inferences from this work and neglecting individual variation with groups (African Americans in this case; for critiques, see Harpalani, 2002; Spencer, Cross, Harpalani, \& Goss, in press; Spencer, Noll, Stoltzfus, \& Harpalani, 2001). In his book, Shades of Black, William E. Cross (1991) provides an excellent overview of diversity in African American identity in response to the historical relationship described by Ogbu (1978, 1990). Moreover, Cross (1991) debunks many myths about Black self-hatred, slavery and its consequences, and the relationship between racial identity and self-esteem.

Within-group diversity is a key issue with regard to both historical delineation and psychological coping strategies. For example, Latinos, as a group, would be split across the taxonomic categories noted by Ogbu (see Gonzales, 2000). Many are recent voluntary immigrants and thus would fit best in the immigrant minorities category (e.g., recent immigrants from Central and South America), and some may also fit in this category but have the additional challenges associated with refugee status (e.g., Cuban Americans). Others may fit better in category of subordinate minorities (e.g., Puerto Ricans, some Mexican Americans). It is important to understand the historical relationship of particular Latino groups to this country, and also not neglect variation within these groups, even if the historical circumstances are the same.

Similarly, Asian Americans also constitute a diverse group with regard to history of immigration. Although most (but not all) Asian Americans would best be described as immigrant minorities, there are significant differences in their particular immigration histories, even within groups (Prashad, 2000; Takaki, 1998). Waves of immigrants from Japan, China, South Asia, and other regions began arriving in the United States in the late 19th century; although immigration from these ar- eas was outlawed by the early 1920 s, descendents of these early immigrants remained in America, and many have retained their particular ethnic identities (Takaki, 1998). The immediate post-1965 wave of Asian immigrants consisted largely of educated professionals who were granted occupational preferences by the U.S. government. This group formed much of the basis for the "model minority" myth of Asian American academic achievement. However, more recent Asian immigrants, arriving mainly on family rather than occupational preferences, are often less educated, poor, and do not fit this stereotype (Prashad, 2000). Moreover, the "model minority" stereotype has also obscured many of the challenges faced by Asian American youth (Takaki, 1998; Prashad, 2000).

Additionally, the history of Native Americans in the United States, which consists largely of cultural and physical genocide (Churchill, 1994), must be taken into account. Also, as noted earlier, whiteness should not be normalized and the history of Whites as a racial group in America must be understood thoroughly to explain the current privileges and challenges of White youth (see Spencer, Silver et al., 2001). The new field of whiteness studies is particularly illuminating and helpful in this realm (e.g., Haney Lopez, 1996; Harris, 1993; McIntosh, 1989).

\section{Research on Youth of Color: Recurring Conceptual Flaws}

Historically, research on youth of color has been characterized by recurring conceptual flaws (Spencer \& Harpalani, 2001; Spencer, Noll, et al., 2001). Often, these populations are labeled as "nonnormative" or implicitly viewed as "pathological." The characteristics of the majority group, White Americans, are typically viewed as the normative standard by which all non-White groups should be judged. For youth of color, and particularly African American youth, normative developmental experiences are often ignored or misunderstood. The prevailing deficit-oriented perspective focuses on negative outcomes and ignores the resilience demonstrated by many youth of color. This view also misinterprets how youth make 
meaning of their own experiences, instead substituting assumptions of cultural deficiency (e.g., Fordham \& Ogbu, 1986). Many different manifestations of structural and symbolic racism, economic challenges, and other barriers often characterize the environments encountered by minority adolescents (Swanson \& Spencer, 1998), but these should be viewed as adverse conditions of stress rather than cultural characteristics. These factors affect adolescent perceptions of self, other, and future life prospects and must be considered without pathologizing the youth themselves.

Lack of cultural competence is another major flaw in scholarship on youth of color. Cultural context has often been neglected in the study of human development and education. In a paradoxical way, this is particularly true of research on ethnic minorities, and particularly African Americans. Ethnic minority status may, on the surface, prompt the researcher to consider issues of culture and context; however, scholarship lacking a coherent, comprehensive theoretical framework often obscures the most salient issues rather than shedding light upon them. Although it often refers to the skills necessary for a favorable therapeutic relationship, cultural competence is also a critical factor in the design and interpretation of research, as it impacts the strategies used particularly in working with non-White populations. Adolescents from diverse backgrounds have a variety of understandings of family, school, and neighborhood experiences which cannot be understood with simplistic, nonnormative cultural formulations (e.g., Fordham \& Ogbu, 1986). Although culturally nuanced perspectives are necessary to understand social and psychological experiences of diverse populations, such an understanding must include careful attention to assumptions about normative developmental experiences, which are too often neglected in research on non-White youth (Harpalani, 2002; Spencer \& Harpalani, 2001).

Finally, discussions on youth have often lacked a developmental perspective, and this is particularly the case with youth of color. African American children, and male adolescents in particular, are treated as "miniature adults" rather than as growing and developing beings. A static, decontextualized approach to diverse youth exacerbates interpretational errors and perpetuates stereotyped assumptions. Researchers should not only be cognizant of these, but also explicitly address issues of development, context, and ethnicity in their conceptualization and design of research (Swanson, Spencer, \& Petersen, 1998). Such work will facilitate research that is designed and conceptualized more soundly, and it will positively impact the application of research findings.

\section{Mitigating Conceptual Shortcomings in Research}

In order to address traditional shortcomings in research on youth of color, we propose several key steps. First, there should be a focus not only on problem behavior, but also on resilience, the attainment of positive outcomes among high-risk youth. The notion of resilience, along with the challenges in studying it as a phenomenon, has been addressed thoroughly by Suniya Luthar (Luthar \& Cicchetti, 2000; Luthar, Cicchetti, \& Becker, 2000), Margaret Beale Spencer (Connell, Spencer, \& Aber, 1994; Spencer, 2001; Spencer, Cole, Dupree, Glymph, \& Pierce, 1993; Spencer \& Cunningham, in press; Swanson \& Spencer, 1991), and their colleagues, with the latter's emphasis specifically on African American youth. Thus, we will not address these issues in detail here, but we do consider them to be significant and noteworthy.

Second, the complexity of race and ethnicity should be acknowledged, and these phenomena should be viewed from multiple perspectives in terms of cultural differences, structural racism, and normative developmental processes such as racial identity formation. Each area of focus derives from a different disciplinary source: cultural differences from anthropology, structural racism in the domain of sociology, and racial identity formation in the realm of psychology. These are seldom integrated into a single body of scholarship. An integrative approach combining all three, however, is essential to understanding issues of race and ethnicity in relation to minority youth development.

With regard to race, our perspective emphasizes the individual's everyday experiences and 
perceptions; thus, we focus on how race is lived on a daily basis and how individuals, including developing youth, make meaning of these experiences. Experiences of race are filtered through larger societal influences such as manifestations of structural racism (see Bonilla-Silva, 1997), as illustrated by spatial and economic segregation, and by encounters of negative stereotyping in the media and in everyday life. Moreover, racial stereotyping is often more complex than stigmatization of mental illness and other devalued statuses. Corrigan and Penn's (1999) distinction between stereotyping (value neutral cognitive categorization) and stigma ("negative" forms of stereotyping) does not work well for racial stereotyping. Racial stereotypes that may seem neutral or positive on the surface, such as the "model minority" image of Asian Americans as high academic achievers (Takaki, 1998) or the superior athletic prowess of Blacks (Harpalani, 1999, 2001), may reinforce other negative stereotypes about respective groups (e.g., Asian Americans as passive, socially inept "nerds" or "geeks," or Blacks as unintelligent, inarticulate "dumb jocks").

In reference to cultural influences, our view is that culture should be understood as a dynamic system and way of living, not as a static entity. Traditionally, culture has been defined as a "complex whole" (e.g., Tylor, 1871/1958, p. 1) or a set of routine practices within a particular socially and historically located group (Cole, 1996). Building on these ideas, we suggest the need to think of culture in a processoriented manner: to focus on cultural socialization and the learning of these practices, along with their meaning to the individual (Lee, Spencer, \& Harpalani, in press). As noted by Ingold (1994, p. 330), "people live culturally rather than ... live in cultures." Understanding cultural influences in this way can help mitigate the pitfall of cultural determinism and inherently emphasizes the changing nature of cultural practices at both the individual and group levels.

Related to these issues, both etic (general to all cultural groups) and emic (specific to a particular cultural group) perspectives on socialization and human development are important (Garcia Coll, Akerman, \& Cicchetti,
2000). It is necessary to recognize that there are normative developmental processes and experiences (as understood by the outside observer) common to all youth and that the meaning attributed to these experiences (and thus the subjective developmental phenomena from the individual's perspective) may vary by social, historical, and cultural context. In a later section, we will address the implications of these different perspectives for assessment of developmental processes.

It is also necessary to be clear on the application of terms such race and ethnicity, which are often used interchangeably. It is generally understood that the former refers to perceptions of observable phenotype while the later refers to cultural background. At times, it is useful as researchers to focus on ethnicity; for example, the culturally specific family experiences of African Americans and African immigrants may differ. However, youth from the two groups may experience similar racial stereotyping and treatment based on the common denominator of race. Depending on the particular circumstances, it may be more useful to focus on one or the other. Nonetheless, it is important to note that many youth and adults may perceive their racial and ethnic backgrounds as interchangeable, if not identical, and thus they are often intricately linked in identity formation. Hence, at times, it may also be useful to consider race and ethnicity together, and it is always important to understand how the two interact in shaping the everyday experiences of diverse youth (for an overview, see Fisher, Jackson, \& Villarruel, 1998, pp. 1157-1166).

The strategies that youth of color employ to cope with these experiences lay the basis for the formation of identity, including racial/ ethnic identity. Of course, this process occurs within both the larger social context of American society and the more local contexts of family, school, neighborhood, and so forth that youth encounter. The processes of coping and identity formation are developmentally contingent; they depend upon youths' prior experiences and previous coping responses and identities. There is also a need to examine gender identity in interaction with race. Studies of gender identity often yield significant 
racial and ethnic differences; for example, Parker et al. (1995) note that Black and White adolescent girls think about body image ideals in very different ways. Therefore, confounding factors create complex interactions between race/ethnicity and gender. All of these issues must be integrated in a larger theoretical framework and must also be teased apart when necessary to understand their salience.

The final primary issue is the need for developmentally sensitive theory that helps to integrate the various perspectives of race and ethnicity. We employ Spencer's (1995) PVEST as an overarching framework. It is a tool for examining human development, focusing on identity formation while taking into account structural factors, cultural influences, and individual phenomenological experiences and perceptions of these contextualized features. PVEST provides us with a model to apply all of the correctives we have described here in our theorizing about diverse youth and also in research design and analysis. Because PVEST is central to both the theoretical and applied aspects of our work, we describe the model in detail in the next section.

\section{PVEST: An Identity-Focused, Cultural-Ecological Perspective}

Spencer's (1995) PVEST combines a phenomenological perspective with Bronfenbrenner's ecological systems theory (1989), linking context and perception. Whereas Bronfenbrenner's (1989) model provides a means for describing multiple levels of context, PVEST directly illustrates life course human development within context. In doing so, it allows us to analyze the meaning making processes that underlie identity development and outcomes (Spencer, 1995, 1999; Spencer, Dupree, \& Hartmann, 1997). PVEST serves as a model to examine normative human development, framed through the interaction of identity, culture, and experience, for youth of all ethnicities. It accounts for the differences in experience, perception, and negotiation of stress and dissonance (or lack thereof). As such, PVEST utilizes an identity-focused cultural-ecological perspective, which integrates issues of social, political, and cultural context with normative developmental processes.

The PVEST model consists of five basic components that form a dynamic theoretical system (see Figure 1). The first component, net vulnerability level, essentially consists of the contexts and characteristics that may potentially pose challenges during an individual's development. Risk contributors are factors that may predispose individuals for adverse outcomes. The risks, of course, may be offset by protective factors (e.g., cultural capital), thus defining net vulnerability for a given individual. For marginalized youth (youth of color and low-resource youth), these include socioeconomic conditions such as living in poverty, imposed expectations such as race and gender stereotypes, and larger historical processes including racial subordination and discrimination. For White youth, privilege itself poses a risk factor, as it may preclude development of coping skills (see Spencer, Silver, et al., 2001). Self-appraisal is a key factor in identity formation; perceptions of the risks one faces and the protective resources available are central to the process.

Net stress engagement, the second component of PVEST, refers to the actual experience of situations that challenge an individual's well-being; these are risks that are actually encountered and must be faced. Available social supports can help youth negotiate experiences of stress; thus, supports are actualized protective factors. Whereas risks and protective factors denote potential entities within the environment, stress and support refer to actual manifestations of these entities, which are experiences in context. In this way, PVEST forges a link between the environment and experience.

Experiences of racism, both subtle and overt, and related dissonance are salient stressors for youth of color; these compound the normative developmental issues that all adolescents encounter (e.g., puberty, identity exploration, peer relationships). Adult role models can serve as supports to help youth cope with these experiences.

In response to stressors and in conjunction with supports, the third component, reactive coping methods is employed to resolve disso- 


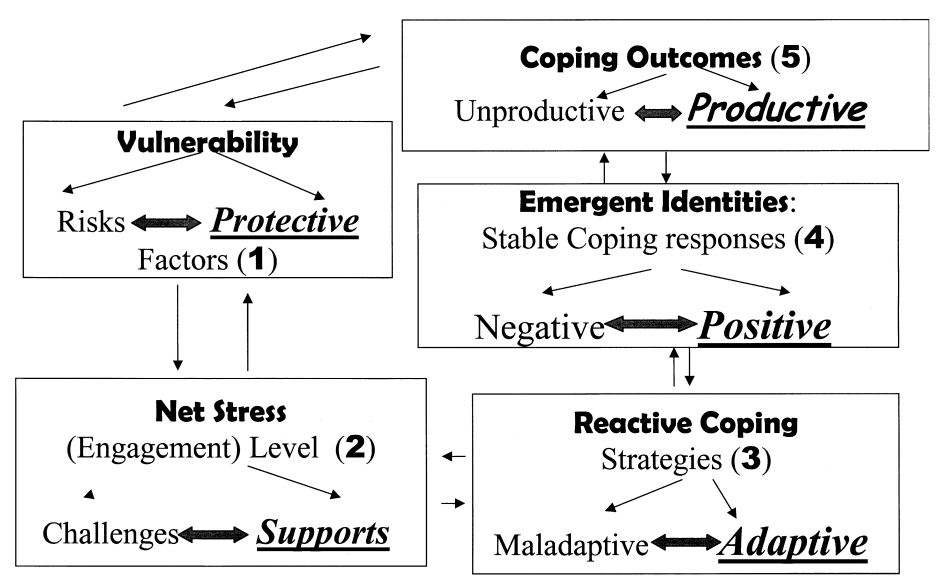

Figure 1. The phenomenological variant of ecological systems theory from Spencer (1995).

nance-producing situations. Normative cognitive maturation makes awareness of dissonance unavoidable and acute. Reactive coping responses include problem-solving strategies that can lead to either adaptive or maladaptive solutions.

As youth employ various coping strategies, self-appraisal continues, and those strategies yielding desirable results for the ego are replicated. Accordingly, they become stable coping responses, and, coupled together, yield emergent identities, the fourth component of PVEST. Emergent identities define how individuals view themselves within and between their various contexts of development (e.g., family, school, neighborhood). The combination of cultural/ethnic identity, sex role understanding, and self- and peer appraisal all define one's identity.

Identity processes are of critical value in that they provide behavioral stability over time and space. Identity lays the foundation for future perception, self-appraisal, and behavior, yielding adverse or productive lifestage, specific coping outcomes, which are the fifth PVEST component. Productive outcomes include good health, positive relationships, and high self-esteem, whereas adverse outcomes include poor health, incarceration, and self-destructive behavior.

The PVEST framework represents dynamic processes that continue throughout the lifespan as individuals balance new risks against protective factors, encounter new stressors (po- tentially offset by supports), establish more expansive coping strategies, and redefine how they view themselves which also impacts how others view them. As noted by Erikson (1969), unresolved issues within one life stage influence future coping and identity formation processes; PVEST aims not only to capture this developmental process but also to place it within its broader social contexts. Although recent scholarship has thoroughly reviewed literature on youth of color (e.g., Fisher et al., 1998) and provided contextually sensitive models to examine developmental competencies among these youth (Garcia Coll et al., 1996), it is the direct, process-oriented delineation of developmental trajectories throughout the life span that makes PVEST unique.

Having presented PVEST as the guiding framework for our analysis of human development, we now turn to the more specific conceptual and methodological challenges of conducting developmentally sensitive research on diverse youth. We apply or emphasize various theme-specific perspectives and theories to closely examine explicit issues (such as racial/ethnic identity development); however, PVEST is always our broader conceptual framework.

\section{Conceptual Challenges: Framing Issues of Context and Identity}

As noted, in order to effectively conduct developmental research on diverse groups, the interaction of context and identity formation 
must be a central conceptual theme. Before considering this interaction from a methodological standpoint, it is critical to acquire a clear understanding of context and identity and their roles in developmental processes. We will focus our attention here on neighborhood contexts and pertinent issues of ethnic identity, two areas highlighted in our recent work. Nonetheless, similar issues can be raised for other salient contexts (e.g., family, school) and identity domains (e.g., gender). To demonstrate the synergy of context and domain, we draw upon literature from earlier developmental processes (e.g., attachment within family contexts) that influence later identity formation. Additionally, we revisit and expand upon these conceptual themes in the section on methodological challenges.

\section{Understanding context}

Van Oers (1998) notes that context is often defined improperly in empirical literature. Researchers often use the term merely to refer to situational influence, ignoring informational meaning-making processes that translate situational influence into interpretation and action. Van Oers (1998) argues for a more dynamic definition of context; one that accounts for these processes and frames the issues in terms of action (i.e., "contextualizing") rather than static influence. Additionally, Dannefer (1992) delineates four components of context: physical setting, social interactions, developing person, and time.

Bronfenbrenner's (1989) ecological systems theory is a process-person-context model that helps to frame the relationship between developmental processes and different levels of context. Ecological systems theory (Figure 2 ) is organized in terms of four levels of context through which developmental processes are mediated: microsystems, mesosystems, exosystems, and macrosystems.

The microsystem involves the interaction of the person with the immediate social and physical environment; examples of microsystems include the home, family, and school settings. All of the levels of contextual influence are filtered through microsystems, where actual experiences of individuals take place. The mesosystem refers to interactions between the various microsystems in a person's life. Mesosystems consist of the network of interpersonal relationships that overlap across the various microsystemic contexts. The exosystem entails more distal influences where the individual is not directly involved. For example, for a young child, a parent's workplace would constitute an exosystem, as it may affect developmental processes without directly involving the child (of course, for the parent, the workplace would be a microsystem). Finally, the macrosystem comprises the societal institutions, such as government, economy, media, and so forth, which form the larger social and historical context for development (Bronfenbrenner, 1989). Thus, ecological systems theory provides a conceptual foundation for examining the multiple layers of context that influence human development and the interactions between these layers.

In recent years, there has been increased attention to context in developmental research (Cicchetti \& Aber, 1998). Historically, psychological researchers have tended to focus almost exclusively on the most proximal constituents of one's environment (Bronfenbrenner, 1989). For example, early developmental research focused primarily on mother-child relationships. The general conclusion has been that the quality of early mother-child relationships determined certain child characteristics (exploration, parental dependence, attachment) that in turn placed the child on a particular trajectory for corresponding life outcomes. Although there has been some attention to the interaction between developmental history and subsequent experiences and available supports (Sroufe, Carlson, Levy, \& Egeland, 1999), the larger systemic factors that impact people of color deserve more consideration.

Applying ecologically driven perspectives to the discipline has broadened theorizing, as well as provided critical insight into the complexity of child development within and across multiple contexts (Spencer, 1995). This can be seen in the application of an ecological perspective to Ainsworth's (1979) attachment research that focused primarily on the mother- 


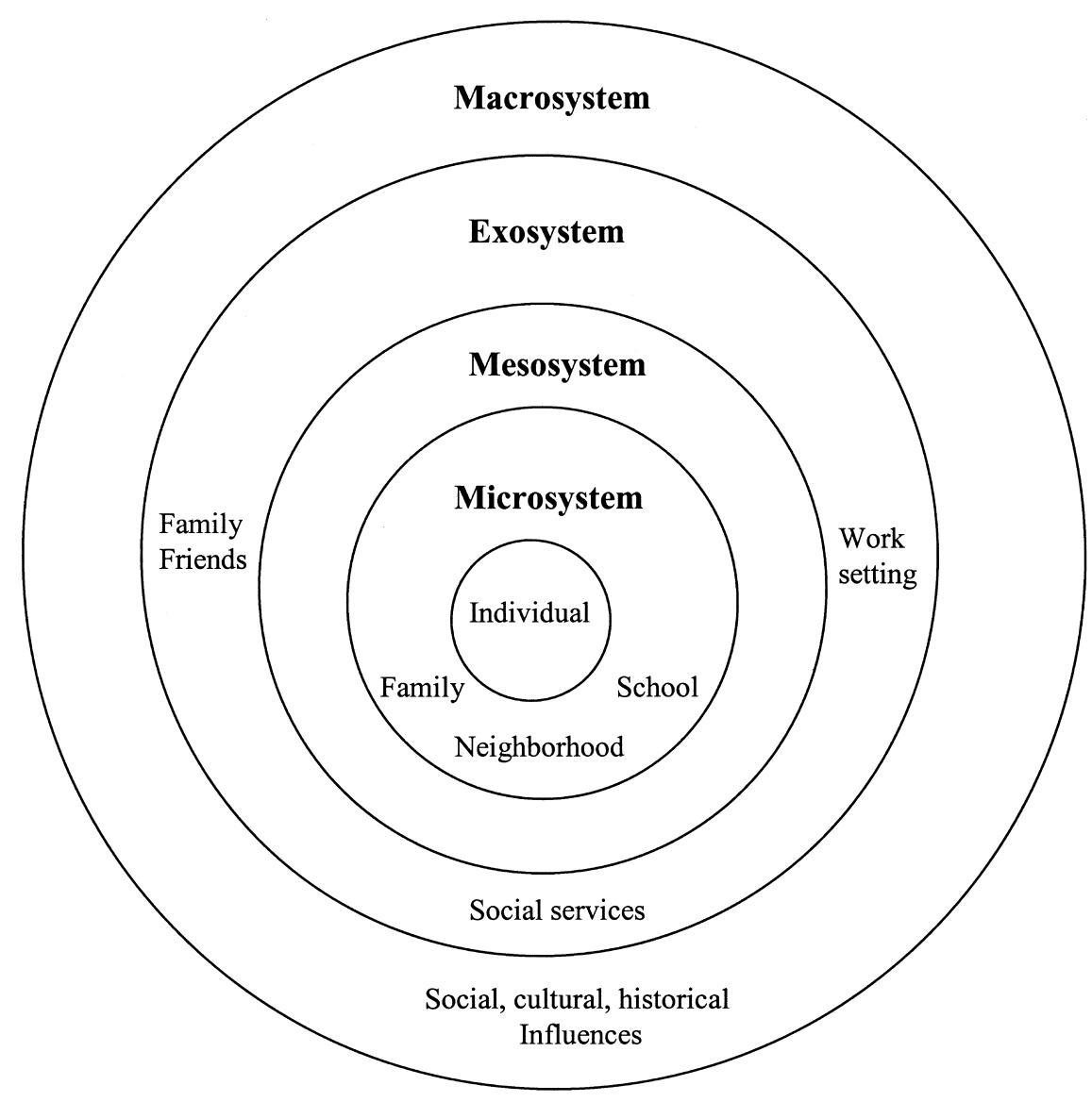

Figure 2. Bronfenbrenner's ecological systems theory (Bronfenbrenner, 1979, 1989, 1993; Spencer \& Harpalani, in press).

child dyad. Further studies have demonstrated that more distal factors such as marital quality, degree of social support, and mother's mental health all play meaningful roles in determining mother-child attachment (Luster \& Okagaki, 1993).

Also, studies of family structure have compared the presence, role, and impact of the father's race/ethnicity. Traditional studies focused primarily on the domestic absence of Black fathers while paying little or no attention to the exosystemic challenges that Black men disproportionately encounter (Spencer, Silver, et al., 2001; Stevenson, 1997). Thus, there is an inadequate understanding and integration of contextual factors, resulting in a deficitoriented perspective emphasizing the shortcomings of Black fathers. Other researchers have attempted to provide a more comprehensive picture of Black males and their familial function by integrating social context factors such as job availability, racism, and role strain (McAdoo, 1988, 1993).

As the previous examples demonstrate, ecology as a theoretical orientation is extremely valuable. Ecological perspectives enable one to address the complex interaction of distal and proximal factors that impact Black males and other stigmatized groups. Further, an ecological perspective emphasizes individual development within the immediate social environment and the impact of the larger social context on this environment (Harrison et al., 1990). By ignoring bidirectional influences between individual and context, researchers tend to draw minimally informed models and 
conclusions. Spencer (1995, p. 38) sums that matter succinctly, "It is crucial to explore outcomes and process as likened to an interaction within particular contexts. Behavior does not occur within a vacuum."

Ecological systems theory suggests several microsystemic contexts that have a large impact on developmental processes. Although researchers have addressed family and school influences, research on neighborhoods is more limited, particularly among scholars interested in developmental processes. Nonetheless, there has been an increase in informed studies of neighborhood effects on development, in part through the work of Brooks-Gunn and colleagues (1993, 1997a, 1997b). Building on the work of Mayer and Jencks (1989), BrooksGunn et al. (1993) examine the impact of neighborhood poverty on child development. Among their findings, they note that the presence of affluent neighbors has a positive impact on the development of children living in poverty. This is a significant factor in racial inequity; as Sampson and Morenoff (1997) note, most Black families with low economic resources live in highly impoverished areas, wheareas most White families in similar economic circumstances have significantly more affluent neighbors and thus experience more economic heterogeneity.

It is necessary to employ an overarching conceptual model that has sufficient theoretical complexity to accommodate the multifaceted exchanges between wide varieties of individuals across wide varieties of neighborhood contexts. The bulk of the studies have focused primarily on the negative life outcomes of people within poor neighborhoods. Little attention has been devoted to the study of neighborhood effects for affluent youth of color. This exclusion from the research limits our knowledge of neighborhood effects and related coping processes.

Future research on neighborhood effects must also address the differential impact of neighborhood by gender. Although girls are experiencing increasingly more pressure from neighborhood context (see Sikes, 1998), many urban and nonurban neighborhoods are environments in which males cannot show signs of vulnerability and must present an exagger- ated masculine identity to maintain respect (e.g., Stevenson, 1997). How is neighborhood perceived and navigated differently by males and females? Given the rates of Black male violence and incarceration (Hawkins, 2002; Herring, 1997) and the increasing rate of suicide in this population (Joe \& Kaplan, 2002), this question is of critical importance. Recent methodological approaches for addressing these issues and concerns are discussed later.

\section{Framing issues of racial and ethnic identity}

The term ethnic identity is becoming more prominent in psychological literature, which is partly due to the work of Phinney (1990, 1992). Building on Cross' $(1971,1991)$ theorizing on racial identity and Marcia's (1966) work on identity statuses, Phinney (1992) devised the multigroup ethnic identity measure (MEIM), which can be used across diverse groups. Nevertheless, even as researchers acknowledge the significance of racial and ethnic identity, there are still conceptual challenges to be addressed.

Perhaps one of the greatest challenges of studying ethnic identity is the fact that there is no standard definition. As noted earlier, the terms race and ethnicity, although understood differently by academics, are often inextricably linked within people's own meaning systems. As Cross (1991) illustrates, the development of Black racial identity involves both an awareness of how one is treated because of one's phenotype (i.e., emphasizing race) and an appreciation of one's own cultural heritage (i.e., emphasizing ethnicity). Thus, while it may be useful for a researcher to tease apart race and ethnicity at times, we must realize that in terms of personal identity, the two are closely coupled and may best be considered together.

Beyond the issue of coupling race and ethnicity, there is still disagreement over the nature of ethnic identity. In an extensive research review that examined over seventy academic articles from psychology and sociology, over two-thirds of the texts identified didn't offer a precise definition for ethnic identity in their studies (see Phinney, 1990). Although some seemed to view ethnic identity as the "ethnic 
component of social identity," others described the most relevant aspect of the concept as whether someone "self-identified," meaning they saw themselves as affiliated with a group. Some defined ethnic identity as a sense of connectedness to those of the same heritage, whereas others described the same concept as based primarily on shared values and customs with a given set of people. The most interesting aspects of these data are not only the varying scope of the definition but also the resulting dilemma when attempting to compare studies that use the term so loosely and diversely.

In addition, many of the studies that discuss ethnic identity are inherently flawed due to research designs and questions that either assume pathology, White standards as norm, or adultification of developmental processes. Historical accounts of minorities, particularly those attempts to understand the formation and influence of ethnic identity, were frequently grounded in one or more of these flawed orientations (e.g., Kardiner \& Ovessey, 1951). Although the 1960s produced an interest in women's, as well as well as minority, rights (Phinney, 1990), remnants of these deficitoriented studies continue (Cunningham \& Spencer, 2000). For example, there is a plethora of questionable "information" on how ethnic identity relates to various societal "ills," such as teen pregnancy, crime and violence, drug abuse, and school failure; but there is very little information on those minority youth who are overcoming obstacles and succeeding (Cunningham \& Spencer, 2000). In addition, much of the available research tends to focus on the validity of the majority while comparing that "standard" to the minority group in question (Phinney, 1990). Moreover, much of the research on ethnic identity has been conducted with samples that did not include adequate numbers of "ethnic" people (Phinney, 1990).

Few researchers have attempted to understand the role ethnic identity plays in the resiliency of these burgeoning adults. We seek to use the PVEST framework to explain the role that factors such as prejudice, stereotypes, privilege, socioeconomic resources and employment/educational opportunities play in ethnic identity development and, more generally, in youth development (Spencer, 1985). Positive identity development, particularly with regard to racial and ethnic identity, is consistently predictive of fewer behavioral problems among youth (see Swanson et al., 1998). Although theories that speak to the complexity of ethnic identity have become more available in recent years, the discourse intensifies with the changing demographics of this country.

From a phenomenological perspective, selfidentification is inherently significant in the investigation of ethnic identity. However, selfidentification, in itself, is not pure; from a developmental perspective, characteristics that others attribute to one's ethnic group are also relevant when defining self (Yancey, Aneshensel, \& Driscoll, 2001). Often, in research designs, people are grouped into categories based on phenotypic traits that may or have not play into how someone defines him- or herself. Many studies do not have the complexity in place for multiethnic people to selfidentify as such, and sometimes research questions themselves come into question as they define a group as dual ethnic or multiethnic before the study begins (Peshkin, 2000). This also relates to the issues discussed earlier relating race and ethnicity.

In related terms, the categories that are typically in place can lead to erroneous conclusions (Posner, 2000). For example, Korean Americans, Cambodian Americans, and South Asian Americans may all be classified as "Asian American" even though there is significant within- and between-group variation present in these categories. Their different histories and locations in American society are important to consider. Although some individuals within all three groups might feel comfortably stating that they are Asian Americans, the label does not take into account the fact that their customs, religious backgrounds, hardships and joys, as well as day to day experiences, could be considerably different. It is difficult in any study of ethnic identity to control for phenomenological differences, and additionally challenging to attempt to quantify similarities based on racial phenotypes that may or may not even be present (Posner, 2000). However, at the same time, it is important to note that different groups such as Korean, Cambo- 
dian, and South Asian Americans may be identified by others as one racial group and thus stereotyped and stigmatized in a similar manner (i.e., the "model minority" myth; see Takaki, 1998). Thus, there may also be a dimension of similarity in their experiences.

In addition, immigration status has been shown to play an integral role in ethnic identity. There is considerable variation in ethnic identity associated with the maintenance of cultural norms and values from one's country of origin. The assumption regarding immigrant youth and their families has historically associated better psychological and societal adjustment with the relinquishing of their prior traditions. Even in light of the more recent contemporary studies that contradict these assertions (see Fuligni, 1998), there is still a need to conceptualize research to address the complexity of studying youth from immigrant and bicultural families. In conjunction with the normative challenges of adolescence, immigrant and second generation youth often develop complex coping strategies to negotiate the cultural dissonance between parental and societal expectations of behavior (Fuligni, Tseng, \& Lam, 1999; Phelan, Davidson, \& Cao, 1991). With PVEST, we aim to provide a developmental framework to capture all these issues.

Ethnic identity is not only a complex issue but also one that many deem "personal" as well. Even the American Statistical Association speaks to the difficulty of attempting to standardize ethnic categories in its collection of data from the census. "As the passage of time has shown, they [these categories] are culturally determined descriptors that reflect societal concerns and perceptions. They are not grounded in scientific, genetic, or anthropological bases, nor are they fixed and unchanging" (quoted in Sawyer, 1997).

Although there are broad definitions in understanding ethnic identity as a construct, a related controversial issue involves assessing what ethnic identity does, that is, how it affects psychological and behavioral outcomes. While the former involves delving into the complex psychological processes associated with group membership or disassociation from a group, the latter represents developing frame- works for understanding the influence of youths' ethnicity identity (i.e., cultural connectedness) on outcomes such as self-esteem or academic achievement (Posner, 2000). Knowledge of a youth's ethnicity as a categorical factor provides little information about how salient membership in that group is or the stressors he or she encounters that are related to ethnicity (Swanson \& Spencer, 1998). Some work in this area has been conducted; for example, Spencer, Noll, et al. (2001) have found that a positive sense of cultural identity among African American youth is associated with higher academic performance. This contradicts the "acting White" hypothesis of Fordham and Ogbu (1986), who erroneously contend that Black cultural values de-emphasize academic achievement (see also Harpalani, 2002; Spencer, Cross, et al., in press). It is important to refute these kinds of deficit-oriented assumptions and to gain an understanding of ethnicity as a context-driven and complex psychological construct.

There are numerous challenges in studying ethnic identity. Problems arising from the term's definition influence the research questions posed and the data collection and analysis strategies implemented. Greater emphasis on developmental perspectives and contextual factors would also be useful.

\section{Methodological Challenges of Conducting Developmental Research in Context}

Although it is important to frame the pertinent issues on a conceptual level, these must also be operationalized into effective research methodology that can inform policy. Methodological challenges for research on diverse youth fall into three categories: research design, assessment (developmental processes and context), and interpretation of findings. All of these methodological challenges are linked to the salient conceptual issues discussed earlier.

\section{Research design}

Design challenges fall into the same "garbage in-garbage out" category relevant for any serious research, regardless of the domain, but they are indispensable concerns in behavioral 
research. There is a critical need for a welldefined and clearly articulated theoretical model to serve as a guide for collecting information, and as a mechanism for determining the linkages between predictors and outcomes. This is even more important in population-based behavioral studies than in the physical sciences, as such studies deal with complex and layered questions that are not amenable to isolation in the laboratory. This means that the outcome or response measures of interest and the variables that are hypothesized to act as predictors must be clearly articulated in the model. Variables expected to mediate the impact of predictors must also be delineated. In our work, PVEST serves as a framework to link conceptual and methodological modes of inquiry. Model C in Figure 3 depicts one statistical modeling method (structural equation modeling) that may be used to operationalize relationships between various components of PVEST.

Various latent variables (e.g., V1, V2, V3) are used in representing a single construct (e.g., risk). The strength of a conceptually driven model will provide the foundation for the particular latent variables used. If an investigator is interested in students' engagement in a schoolbased skill development program, latent variables for risk could include frequency of participation early in the program, prior grades (reflecting school motivation and engagement), and mother's education; or, if interested in risks related to school performance, variables could include child's prior grades, school poverty, and mother's education. Variables comprising risk would be predictive of coping methods and subsequent emergent identity. Any construct being examined can be associated with its own set of theoretically and conceptually driven latent variables. Figure 3 (Model C) examines the prediction of youths' emergent identity (e.g., ethnic identity, self-efficacy, self as learner, body image) from a combination of risk factors or by a set of stress variables and as mediated by specific reactive coping strategies.

Another potential impediment particularly relevant for developmental research on diverse youth is the challenge confronted when collecting multiple assessments over time. Be- cause biological and social influences are constantly changing in response to physical growth, psychological development, and new experiences, it is important to look at these differences over time in order to begin examining factors that shape adolescents' individual life trajectories. Within-group longitudinal studies afford an opportunity to examine whether differences in life events, socialization processes, or perceptions of support over time are salient predictors of coping processes, either maladaptive or adaptive.

Very few empirical studies have explored differences over time within groups (ethnic, gender, immigrant), and those that have usually concentrate on some sort of pathology. For instance, although studies of depression in adolescent girls (e.g., Ge, Conger, \& Elder, 2001) provide valuable information about the interaction between puberty and psychological factors, these studies would be more informative if they had looked at these girls over time.

Another confounding factor is long-term participation in longitudinal studies. Youth of color in urban environments are often unable to complete their participation in longitudinal academic research initiatives. In addition to the already intense physical and psychological demands that adolescence places on all young people, social issues of racism, discrimination, inequality, and poverty are daily stresses and salient reasons why youth of color present high rates of attrition in academic studies (Spencer \& Dornbusch, 1990). Further, language and cultural barriers (Phelan et al., 1991), frequent mobility, and lack of sufficient funds to adequately compensate participants exacerbate the problem of "phantom" participants (Hawkins, Catalon, Kosterman, Abbott, \& Hill, 1999).

In recent longitudinal inquires, there has been ample effort to retain low-resource minority adolescents. Proven tactics in the fight to prevent attrition require financial resources. Current research highlights the importance of developing relationships with participants and their families and allowing for additional study days to track school truants or locate missing families (Epstein \& Botvin, 2000). Another strategy could involve adding financial incen- 


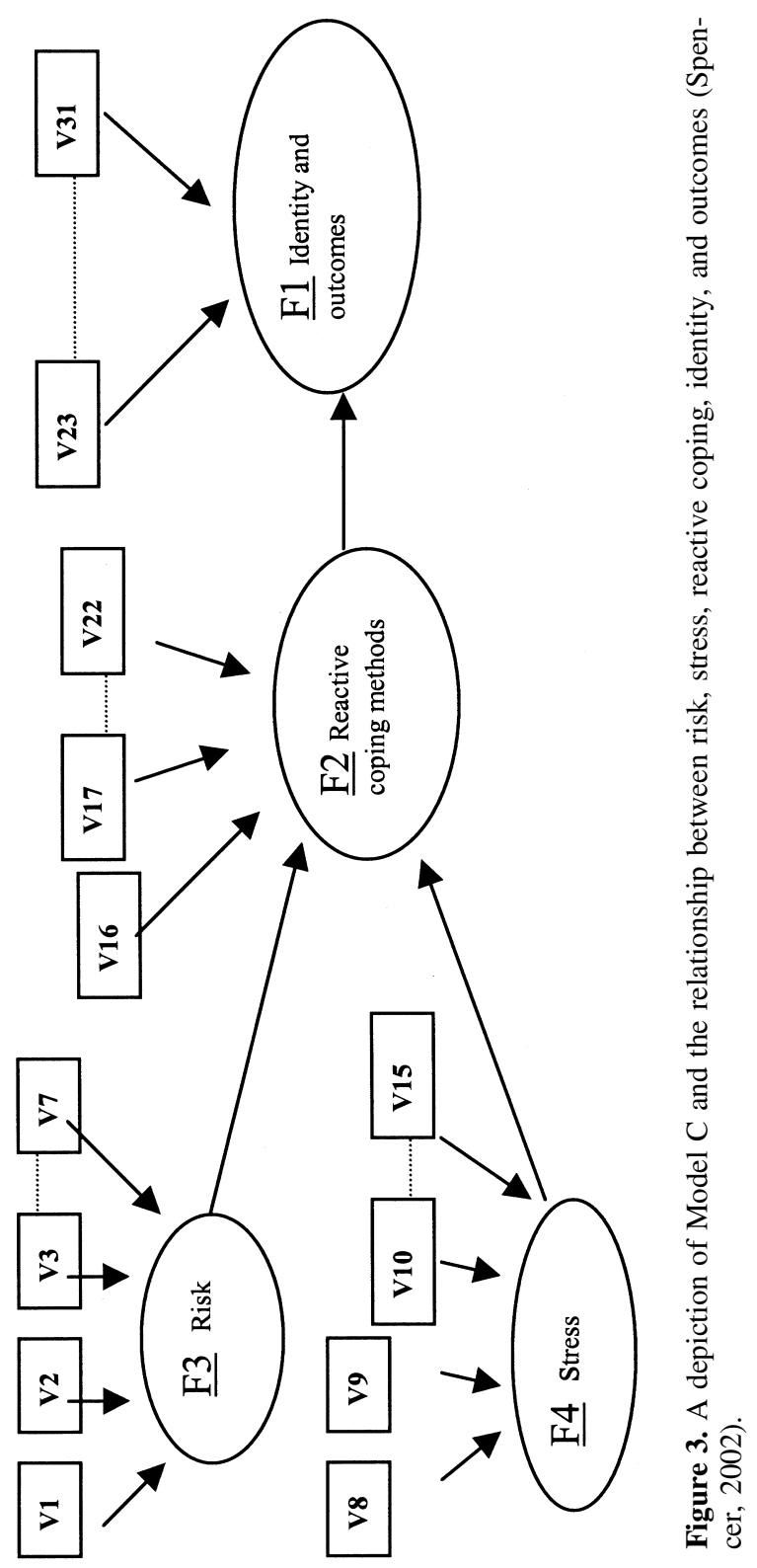




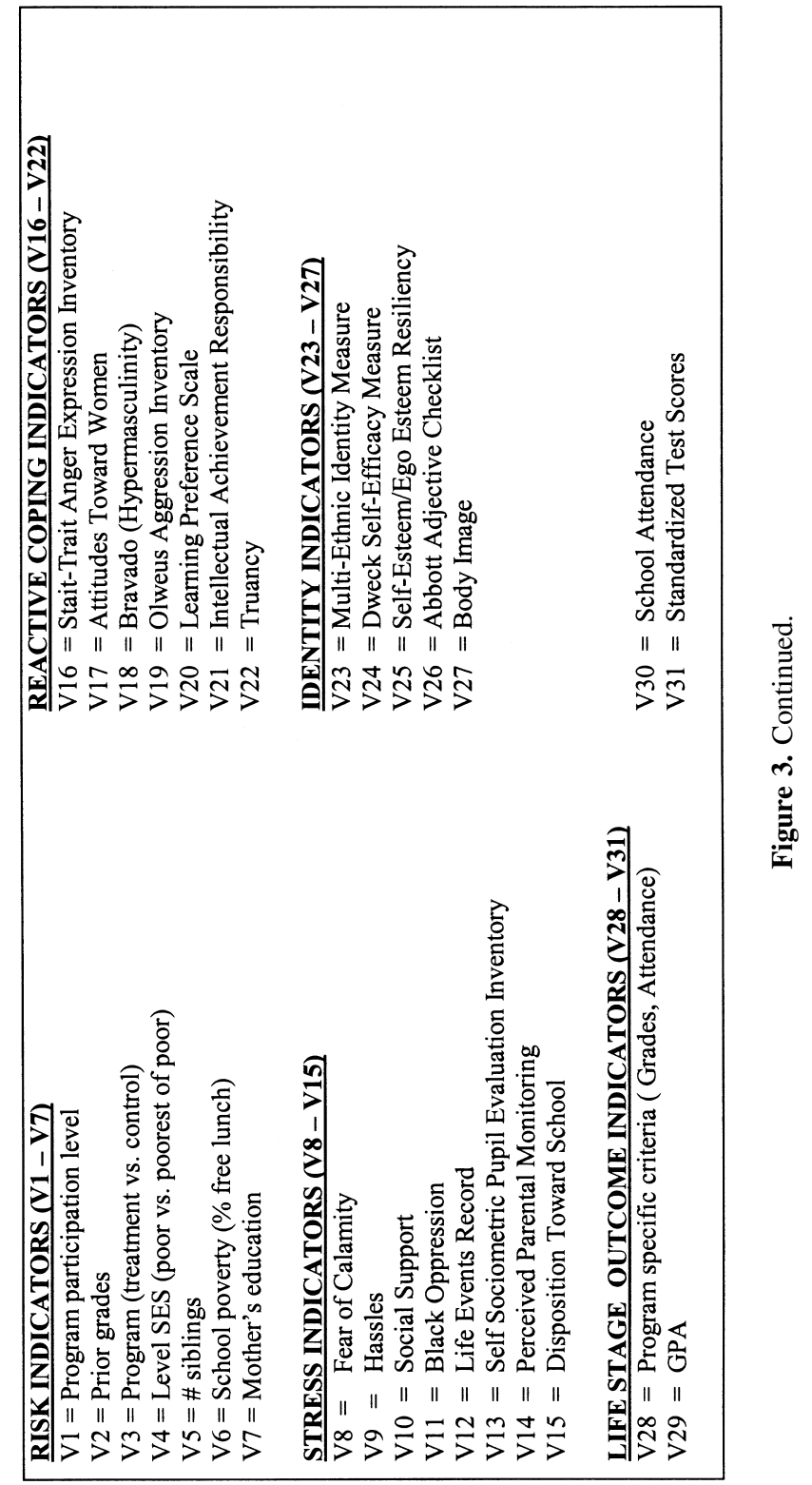


tives for study completion, although the ethical implications of such an endeavor should be considered thoroughly (Hibbs \& Krener, 1996). Hiring multilingual consultants may also be necessary because language and cultural barriers are undeniable factors in study attrition. In addition, concurrently offering programming aimed at strengthening social bonds at school while performing a longitudinal inquiry has proven to be helpful in participant retention (Hawkins et al., 1999).

\section{Challenges in assessment}

Assessment of contextual and developmental variables is another major methodological challenge, for measures collected at any level (e.g., individual, family, school, neighborhood). The complex interaction of context and developmental processes create the potential for misinterpretation. Also, different experiences and cultural meanings ascribed to items within psychological measures are important to consider; these factors suggest an emic (culture specific) approach to assessment, even when salient processes involved, such as coping strategies and identity formation, may be culture general (etic). Measures of individuallevel behaviors or beliefs selected to represent characteristics and behaviors of specific populations at a particular developmental stage should reflect values and experiences of that population, and be presented in such a way that the meaning of the question is understood by both the researchers and study subjects. Otherwise, a meaning mismatch occurs. One strategy to gauge shared meaning is to use a mix of question formats: closed and open ended. For researchers using instruments developed for populations of different developmental stages, ethnicities, and gender, focus groups or a structured content review of item wording for relevant references are recommended. Confusion resulting from misplaced references is not likely to emerge during survey assessments, for example, because subjects will respond based on their interpretation. The researcher is left with the erroneous notion that the answer represents a shared meaning.

Operational definitions are critical to con- ducting valid research, and concepts, definitions, and actual measures must be empirically relevant and salient. For example, academic achievement is traditionally measured by grade point average (GPA) and standardized test scores. However, patterns of school absenteeism may actually be a better gauge of longterm school engagement than GPA, which has been found to be an inconsistent standard of measurement particularly in math and English, due to the variability in grading practices across schools, even in the same school district. In addition, research on school attendance has established the relationship between achievement on standardized tests and school attendance (Lamdin, 1996; New Orleans Public Schools, 1994) and as an early warning sign of potential delinquent activity and educational failure (US Department of Justice, 2001).

In these next sections, we revisit many of the conceptual issues raised earlier, framing them within the rubric of research design and analysis. Our aim is to transition from a broader, theoretical understanding of context and identity development to their tangible application in research protocols.

\section{Assessment of context: The problem of definition}

To illustrate some of the methodological challenges in the assessment of context, we will draw from the literature on neighborhood assessments, including our own work. Assessments chosen to represent environmental influences should capture the complexity of everyday experiences of context. In terms of neighborhood assessments, one way to facilitate this is to balance census tract data with other methods of systematic observation of evaluating neighborhood conditions. As noted earlier, defining neighborhoods or examining neighborhood character is not as straightforward a task as it may seem. There are competing interests that must be negotiated. Researchers must strike a balance between the validity of neighborhood definitions and the degree to which those definitions readily avail themselves to be used in concert with other sources of data and surveillance practicality. 
Problems of definition, as previously noted with ethnic identity and school engagement, are common challenges in conducting psychological and behavioral research; they are also a concern in examining neighborhood effects on youth. Within the rubric of definition, however, formatting issues pose additional challenges that are particularly relevant in analyzing large-scale survey and demographic data sets. For example, in Philadelphia, there are several plausible ways of dividing and defining neighborhoods (see Cartographic Modeling Laboratory, 2001; Hillier, 1999; McMullin, 1975). The 1980 census divides Philadelphia into 289 "neighborhood statistical areas." However, census neighborhood categorization very seldom attempts to preserve "neighborhood" in the sense we discuss it here. The Philadelphia Department of Health recognizes far fewer neighborhoods (45). This neighborhood designation is largely based upon the location of various public health centers throughout the city. Similarly, the Philadelphia Police departments recognize 152 neighborhoods that are largely based on the distribution of police precincts. Both the health center and police precinct neighborhood designations are primarily based on population distribution and do not attempt to capture the character of neighborhood as defined by shared geographical space.

Burton, Price-Spratlen, and Spencer (1997) also raise the issue of neighborhood measurement. They suggest that researchers must begin to attempt to understand neighborhood context from a phenomenological perspective, as residents see it, in order to gain a more accurate picture of neighborhoods effects. Often, the tendency of researchers has been to impose adult worldviews onto children and adolescents. To do so is to hold youth to standards that they may not be psychologically mature enough to meet, or to classify youth behavior as deviant without a clear understanding of intent, rationale, or motive (Spencer, 1995). Coulton, Korbin, Chan, and Su (2001) also discuss some of these issues.

Thus, youth perception of ecological risk is "uniquely important" to understanding and predicting outcomes. For example, Stevenson (1997) describes how African American youth are "missed" and "dissed" by mainstream Amer- ican society and how neighborhood factors affect how African American youth become "pissed" while managing their anger. Black youth are "missed" as media-based images and negative racial stereotypes distort the meanings of their social and affective behavior. These unique behaviors are thus devalued and viewed with disdain ("dissed").

In conjunction with these misrepresentations, many Black youth reside in high-risk neighborhoods where anger display may be an appropriate and necessary coping strategy. Indeed, anger display can become a form of competence for social and emotional viability in certain contexts, such as high-risk neighborhoods (see also Luthar \& McMahon, 1996). However, such displays of anger may be diagnosed as pathological if not properly understood. In terms of understanding conduct disorder, Richters and Cicchetti (1993) also discuss this issue.

Another related concern is youths' experience of violence, both as victims and as witnesses. Several commentators have discussed this issue in detail (Lynch \& Cicchetti, 1998; Shakoor \& Chalmers, 1991; Spencer, Dupree, Cunningham, Harpalani, \& Munoz-Miller, 2003). Although much of the focus has been on low economic resource Black youth in urban neighborhoods, violence is also a significant issue for more well to do suburban youth, as illustrated by recent incidents such as the one at Columbine High School in Colorado. The vulnerability of upper middle class (and predominantly White) youth in more affluent suburban neighborhoods should also be investigated (see Luthar \& Becker, 2002; Luthar \& Latendresse, 2002).

As one reviews the literature, one is confronted with multiple definitions of neighborhood that capture the essence of neighborhood social context to varying degrees. Many neighborhood studies almost exclusively define neighborhood through the use of census tracts and census data. For example, the vast majority of research on neighborhood effects has operationalized poor or disadvantaged neighborhoods as neighborhoods with over $40 \%$ of residents below the poverty line. Although this definition makes for relatively easy comparisons of neighborhood and individual level data as it relates to census variables, it still 
does not address fundamental questions as "What is a neighborhood and who decides what constitutes a neighborhood-individual or researcher?" This is particularly relevant as skewed or imprecise definition of neighborhood raises concerns regarding research validity. Huckfedlt (1983) provides a thoughtful definition/discussion of neighborhood as he acknowledges the limitations of census data:

This operational definition of neighborhood social context does not equate a neighborhood with a cohesive community of friends and acquaintances. Such cohesive community of friends and acquaintances sometimes exist, but they are tangential to the present argument, and they cannot be measured with census tract data. The neighborhood as it is conceived here refers to the shared geographic locale of a residential grouping, and the neighborhood social context refers to the population composition of the people who live in the neighborhood. This neighborhood definition subsumes the cohesive community but does not depend on it. The definition is designed to capture the "inescapable social relations of any geographic based social collectivity." (p. 652)

There are at least two issues of concern here. First, researchers must be able to obtain data that are not necessarily spatially related in a spatially referenced format. Second, spatially referenced data may be limited in scope; it may not necessarily provide meaningful information concerning the ecological contexts of neighborhoods. What was seemingly a straightforward task requires a great deal of thought and consideration. The question then becomes how can one maximize spatially referenced census data while at the same time get an accurate measure of neighborhood context?

Our work with the Neighborhood Assessment of Community Characteristics (NACC) survey instrument (Spencer, McDermott, Burton, \& Kochman, 1997; more generally, see Brooks-Gunn et al., 1997a, 1997b) is one starting point in this effort. NACC is a neighborhood level survey consisting of 125 items regarding the character of a neighborhood on multiple domains. Trained observers complete the protocol using the "windshield observation technique." Drivers and observers drove a one-half mile both north to south and east to west from a fixed point in a neighborhood. Various community characteristics, such as housing quality, types of advertising, amount of green space, crowds, recreational facilities, number of street lights, and so forth were noted on the protocol. All of these data will be analyzed in conjunction with extensive psychosocial assessments of low resource urban youth living in these neighborhoods; these assessments include measures of academic competence, psychological well-being, and perceptions of context, including neighborhoods.

Without such measures as NACC, many studies of neighborhood effects have underestimated the role of neighborhood ecology as tract level census variables are too "removed" from the context to adequately explain the neighborhood ecology. Burton et al. (1997) elaborate on the limitations of census data: "census-tract data comprise geographic units that are much larger than the developmental neighborhood niches of children ... census tracts as the unit of analyses for neighborhoods does not facilitate the range of heterogeneous outcomes evident in the smaller geographic units in which children live" (p. 137). Additionally, when combined with proper psychosocial assessments, measures such as NACC allow us to begin understanding the linkages between neighborhood contexts and identity formation. As noted, PVEST provides the overarching framework to link the two sets of measures.

\section{Assessment of developmental processes}

Although research in child and adolescent development has begun to address cultural diversity and contextual factors, investigators must still analyze the underlying assumptions that drive studies, which as noted earlier, are often framed from a deficit-oriented paradigm. Also, there remains the need for greater scientific rigor in data collection, measurement, and interpretation of findings. In terms of designing research studies of typical and atypical development, an understanding of the processes by which development takes place makes it easier to identify and address the following:

- operational definition of concepts being studied and the development of assessment instruments, 
- alternative interpretations of concepts being studied and their relationships to other variables, and

- standards against which development should be assessed or measured.

In very general terms, the most basic processes of human development are similar across all groups, calling for an etic perspective. Nevertheless, the unique experiences among members of diverse groups may determine the ways in which typical developmental processes can lead to diverse outcomes. These unique experiences have implications for instrument development and measurement, thus also necessitating emic approaches. In particular, researchers must move from operational definitions of race and ethnicity based on categories for developmental comparisons to more dynamic operational definitions of the different cultural aspects of the racial and ethnic groups being studied. A dynamic approach would use variables that capture early parenting skills that are conducive to optimal developmental outcomes within a particular cultural context. Researchers should begin to develop more complex research questions as their analyses begin to take into account the interactions among cultural factors and ethnic groups being studied (Garcia Coll et al., 1996, 2000; Garcia Coll \& Magnuson, 1999).

Several studies have attempted to establish mechanisms for assessing the complexities of data collection and analysis. Acknowledging the considerable variation within and between ethnic group self-identification, Yancey et al. (2001) attempted to update and use a standardized ethnic identity measure presumably not plagued by many of the problems outlined above. Yancey's (1995) study also attempts to go beyond the confines of school to identify young people who might be alienated from that setting.

Phinney's (1990) MEIM was designed to capture "variation between and within ethnic groups" and distinguish those factors that covary with ethnicity from those that are actually elements that comprise it. Two of these factors, affirming one's membership in a group and participating in group activities, were rel- evant to ethnic identity in all groups except Caucasians. Perhaps the affirmation of "whiteness" has a negative connotation that does not exist for other groups (Phinney, 1990). Although subsets of Caucasian groups, such as Italian or Irish American, might have heightened their results, the MEIM has been shown to be one of the most effective means to date by which ethnic identity can be measured as a construct across groups.

Nonetheless, development of other measures is an important challenge for the $21 \mathrm{st}$ century. In particular, finding ways to decouple racial and ethnic identity, which as noted earlier are often linked together within individual self-perception, may elucidate how group cultural activities help youth of color cope with everyday stressful encounters associated with racial minority status.

Interestingly enough, a study performed among White teenagers attests to the notion of a "cultureless" White population (Perry, 2001). Through ethnographic research and in-depth interviews at two high schools, one predominately White and another multiracial, researchers found that students who comprised a White majority saw themselves as the norm, the standard from which other populations should be judged (Perry, 2001).

As noted in the introduction, such normalization of whiteness is a major problem in research agendas and perhaps the major impediment to gaining a full understanding of development among diverse youth. White racial and ethnic identity must be examined as one of many diverse groups, not as a standard for others to be judged. The work of Janet Helms (1990) has proved very informative and critical in this realm, and others are continuing to build on this work (e.g., Dabrowski, 1983; Rowe, Bennett, \& Atkinson, 1994). The expansion of whiteness and White identity studies should be a major theme of research on diverse groups in the 21 st century, and these should include both the sociohistorical analyses cited earlier and the identity-focused studies noted here.

A broader, developmental perspective also necessitates the assessment of processes that are precursors to identity formation. Recent research on experience-dependent brain de- 
velopment reinforces the idea that there may be sensitive periods during which the nature of a child's experiences may influence the child's subsequent interpretation of developmental events (Pollak, Cicchetti, \& Klorman, 1998).

For example, the development of secure attachment relationships in infancy has implications for social and emotional development and identity formation throughout the life course (e.g., ability to get along and work well with peers in school). There is a body of research highlighting the potential long-term effects of insecure attachment during infancy including poor social cognition and delinquent behavior (Cicchetti \& Carlson, 1989). As would be expected based on attachment theory, children who experience insecure attachment (e.g., as a result of maltreatment) also experience disturbed peer relationships when they are older in the form of heightened aggression, inappropriate anger and low prosocial behavior (Trickett \& McBride-Chang, 1995).

Research with diverse groups may occasionally require alternative interpretations for established constructs. The constructs of racial awareness and identity, for example, may on one level be seen as risk variables. However, a child may have varying experiences of race as a risk factor at different points in development. Developmentally speaking, African American toddlers and young children may not conceive of themselves as having racial identities. However, they may exhibit precursors to racial identity. For example, African American children show awareness of color connotations, or concepts, as early as age 3. That is, they often associate negative attributes with black animals or dark-skinned persons when compared with identical white animals or lightskinned persons (Spencer \& Horowitz, 1973). Race awareness is related to the child's social cognitive ability to take the perspective or point of view of another.

Social cognitive ability develops with age. There appears to be a developmental pattern in the understanding of color connotations as a consequence of increases in social experiences and social cognition (Spencer, 1982). Three-year-old children of all race/ethnic backgrounds are generally Eurocentric in terms of racial attitudes, racial preferences, color con- cepts and connotations. However, for Black children, an Afrocentric pattern of attitudes and preferences begins to appear at age 5 and continues through age 9. If early childhood experiences lead to developmental delays in the social cognitive ability, and consequently the racial awareness, of the child, the child may lead to a different phenomenological experience of being a person of color (e.g., a member of a disfavored racial group). However, different developmental patterns emerge when socioeconomic status is taken into account. Middle-income Black children were generally Eurocentric in terms of racial attitudes, racial preferences, color concepts and connotations at age 3 , whereas low-income children were neutral on the same dimensions at the same age. After age 3, both low- and middle-income children showed a clear Eurocentric orientation for color concepts. However, middle-income children became progressively more Afrocentric through age 9, whereas low-income children showed a pattern of neutrality.

Such an understanding of racial attitudes in the context of social cognitive development suggests that some explanatory power can be lost when race (used as a categorical variable) is considered as a risk factor without additional variables that capture the child's experience of race (i.e., variables that capture the child's understanding of color connotations, racial attitudes and preferences). That is because the processes of identity development may also be indicators of the processes by which a child copes with her or his experiences of race (see Spencer, Cunningham, \& Swanson, 1995, for a description of "identity as coping"). For instance, research suggests that there is a difference between children's ability to perceive color connotations and their acceptance or internalization of those color connotations (Spencer, 1999). Depending on the phenomena being studied, a child's internalization of negative stereotypes associated with being a member of a particular racial group may be a more important risk factor than the fact that a child belongs to a particular racial group.

In some instances, research with diverse groups requires that new "norms" be estab- 
lished. Often "norms" serve as benchmarks for determining whether behaviors and abilities are at, below, or above average. Without norms for diverse groups, children from different groups may be mistakenly identified or overlooked for intervention when their behaviors or abilities do or do not fall within expected norms. For example, with regard to motor development, some research suggests that there are group differences in the achievement of gross motor skills (e.g., Capute, Shapiro, Plamer, Ross, \& Wachtel, 1985). From the perspective of assessment and measurement, this can be problematic, for example, in the context of research on child maltreatment. As Perry and colleagues (Perry, Pollard, Blakeley, Baker \& Vigliante, 1995) explain, a traumatized child may, over the course of time, exhibit motor hyperactivity, anxiety, behavioral impulsivity, sleep problems, tachycardia (an abnormally fast heartbeat), hypertension, and a variety of neuroendocrine abnormalities. In their review of research on the developmental impact of abuse and neglect on children, Trickett and McBride-Chang (1995) found limited evidence regarding the physical and motor development of abused and neglected infants and young children. The research has not been systematic or conclusive. Nevertheless, as noted, there is evidence of somatic complaints among sexually abused children.

On the other hand, Capute et al. (1985) found that Black infants are more advanced in motor development when compared with White infants. Failure to attain motor milestones at the appropriate time may indicate central or peripheral neuromuscular disorders. Capute et al. (1985) found that Black children attained gross motor milestones earlier than White children. The difference was, on average, a less than 1-month difference before walking. Their research suggested the following order in terms of emergence of advancing gross motor skills: Black females, Black males, White males, White females. The authors' own interpretation of the findings suggests that "If racial differences are not recognized when upper limits are set... Black children may be classed 'normal' and thereby delay diagnosis and/or treatment" (p. 641).

Capute et al.'s (1985) study findings also suggests that socioeconomic status (SES) should be taken into account when interpreting the research. After accounting for race, the differences across SES were markedly diminished and only a slight trend between SES and gross motor achievement remained. There was, however, a relative under-representation of Blacks in the upper SES groups; thus data on motor development for Black children primarily represented a lower SES group.

As the examples offered suggest, integrating a developmental perspective into research on diverse groups requires a more articulated understanding of the processes by which development takes place. In particular, related to the earlier points about "how people live culturally" (quoted in Ingold, 1994, p. 330), there is a need to acknowledge cultural factors as

an active part of the changes and influences on developmental processes... This new treatment of culture reflects the need to "unpackage" culture, that is to consider culture as a multidimensional evolving source of influence on developmental processes within any culture rather than as a monolithic nominal variable. The unpacking of culture also requires researchers to operationalize culture in concrete variables. (Garcia Coll \& Magnuson, 1999, p. 3)

There is also a need to create new "norms" both in terms of typical development (motor, cognitive, social) and the types of data that are typically collected as part of a battery of measures that include particular constructs (e.g., attachment, race, etc.). In the absence of such strategies, there is potential for misinterpretation of the developmental processes that underlie these constructs in diverse groups.

\section{Challenges of interpretation}

In addition to assessment challenges, several confounding factors can affect interpretation of findings. First, as previously noted, definitions of terms and constructs frequently vary. For example, what exactly does "poverty" mean? One can use a standard definition based on income, but this may miss several salient factors, such as length of time in poverty and employment. Bronfenbrenner (1985) notes that poverty is often a transient phenom- 
enon; families move in and out of poverty. Moreover, Conley (1999) notes the importance of aggregate wealth, as opposed to income, for a variety of Black-White racial disparities.

In addition, children's development does not occur in contexts that are randomly allocated; this may cause estimates to be biased in unpredictable ways. The interactions between large numbers of complex variables are often difficult to decipher. Moreover, neighborhood context may influence and be influenced by youth behavior (Manski, 1993). Creating and interpreting models for such phenomena is a challenge. On a conceptual level, the PVEST framework allows for management of this complexity. However, because true experimental designs are rare in developmental science, determination of causality is always an issue.

The incorporation of complex and nuanced contextual variables itself brings about more challenges. There is a need to measure predictors of how children came to live in neighborhoods. Relevant parenting variables, such as parental decision-making and support, parenting practices, and parental mental health may play a role, and it may be difficult or burdensome to measure all of these. Statistical models should add a term for unmeasured familyspecific influences on choice of context.

Additionally, perceptions of context, in addition to contextual variables themselves, must be interpreted properly. Definitions of neighborhoods may not correspond to any of those given earlier, particularly for adolescents. Depending on the school district, adolescents may attend school in neighborhoods that are characteristically different from their residential neighborhoods. Thus, adolescents' sense of neighborhood may change several times in 1 day, 1 week, and so forth. Neighborhood effects will be biased if gathered from only one source (e.g., self-report or census tract only). Researchers should remain cognizant of the distinctions between perception and other systematic ways of measuring context.

Finally, as a methodological concern, issues regarding the handling of missing data for student academic outcomes have not been adequately addressed in the educational literature. Our efforts to obtain school district administrative data has revealed patterns of missing data particularly in schools with high proportions of low economic resource students (students living in poverty as designated by federal guidelines). This silent, absent group of students is the most underrepresented group of adolescents in the research literature in part, because of these issues. It is no wonder that programming and interventions designed to target atrisk youth are often ineffective and sometimes even harmful. Research studying the effectiveness of these programs has been conducted only with participants who were there to receive it, and thus, not inclusive of the most vulnerable youth (Epstein \& Botvin, 2000). The high attrition rate at many urban schools adds to this problem.

In order to conduct viable and productive studies, researchers who focus on adolescent school outcomes should understand the procedures used to assess and store student academic data and critically assess the implications of analyses based on data missing for certain subpopulations. This topic is of great importance in educational research because reliance on academic measures with missing data on subpopulations of interest may severely impact generalization of findings.

\section{Social Policy: Conceptual and Methodological Issues}

All youth have the potential for psychological vulnerability and maladaptive coping (Anthony, 1974). However, differences in the expression of vulnerability are possible. Low-risk environments may offset the expression of vulnerability, while high-risk environments increase the probability of maladaptation. As noted, structural conditions linked to poverty, race, and ethnicity frequently result in unsupportive environments. For economically disadvantaged youth, the developmental crises and stresses of this period often are compounded by unstable factors in their immediate context (Spencer \& Markstrom-Adams, 1990). Effective social policies for poor and ethnic minority youth support greater resilience and reduce the likelihood of adverse outcomes by implementing changes relevant to the structural conditions. Thus, supportive youth policies have the potential to mitigate high risk environments. 
Policy makers depend upon social science data for generating social, mental health, and child welfare policies. Social policies address larger social concerns such as poverty. Mental health policies address issues of prevention and treatment such as disparities in diagnoses, while child welfare policies focus on factors imbedding physical and emotional safety. Regardless of the policy focus, supportive data are too frequently produced by investigators who lack a clear understanding of the interactive effects of structural conditions, historical forces, psychological processes and a priori, deficit-oriented assumptions (e.g., assumed family pathology). As a consequence, policy proposals often fall short of their envisioned goals.

Combined with educational failures and minimal or inconsistent supports, factors such as adolescent crime and drug abuse combine to create long-term social devastation. Methodological issues impact policy decisions by what is identified as the problem, how it and substantiating factors are measured, what is utilized in the analytical approach, and what variables are not included at all. Many behavioral problems among ethnic minority youth often stem from educational and economic inequities. Policy makers have the potential to develop programs that could reduce the structural causes and multicausality factors, but also promote attitudes and behaviors that help communities and families support individual functioning (Spencer \& Swanson, 2000). To accomplish these tasks with respect to poor and African American youth, it is necessary for policy makers to understand how institutions and conditions outside the developing child and family operate to either promote or prevent untoward behaviors (Greenberg, Domitrovich, \& Bumbarger, 2001). Additionally, policy makers should comprehend the salient processes of child and adolescent development and identify multiple points for resiliency-promoting intervention. The PVEST framework provides a conceptual tool to aid in this effort.

In considering methodological and conceptual issues relevant to ethnic minority youth, the most elusive challenge is that of latent biases held by investigators and policymakers. Values influence what behaviors are identified as problems and underlie scientific proce- dures used in exploring and interpreting the etiology of the behavior. The results of biased or inadequate research have occasionally led to inefficiently planned policies and programs. Due to the enduring problem-focused perspectives, particularly among policies, youth often become identified by the behavior. A priori assumptions about etiologic and contributing factors can limit the conceptualization of influences inconsistent with the assumptions (see Swanson \& Spencer, 1998). For many years, for example, it was difficult for investigators to acknowledge findings that demonstrated single-parenthood as nonpredictive of many child and adolescent problems. It was assumed that a father-absent household was an abnormal family and therefore understandably responsible for producing abnormal children. Family strategies for compensating (i.e., extended kin) were not embedded in the conceptualization. In essence, while family structure became the target of presumed etiology, other contexts such as the school environment went unexamined. Although it is important for investigators to recognize and challenge their own assumptions, it is also important in a policy arena to at least question especially intuitive findings, suggesting a strong fit with unexamined values or a priori assumptions.

\section{Social policy: Initiatives needed}

We have several recommendations for research design and programming aimed at understanding behavioral outcomes and promoting resilience. They are presented within the PVEST framework, with a focus on reducing risks and stressors that will facilitate adaptive coping and more productive outcomes.

Reduction of risk. Public and private policy makers should recognize and understand that the coping behavior of diverse youth is related to macrosystemic factors such as racial biases and privileges, tangible experiences involving these factors (i.e., experiences of being stereotyped), and individual coping responses to these experiences as mediated through available social supports. Often, only the latter are viewed as problems, thus placing emphasis on individual behavior. Etiological considerations are 
often skewed toward individual attributes rather than socially endemic factors. The conceptualization of a problem is particularly salient in shaping laypersons' perspectives and in identifying prevention or intervention strategies. For example, treatment programs focusing on delinquency reduction can approach the problem from a perspective of youth coping with uncontrollable contextual factors, or from a viewpoint in which the behavior is defined as reflective of innate characteristics of the youth. Strategies utilized for treatment will reflect the perspective most closely endorsed. Therefore, it is critical to question simplistic assumptions about maladaptive behavior and to understand the relationship between larger societal influences, the tangible experiences of youth that reflect these influences, and the strategies that youth employ to cope with these experiences. Rather than focusing merely on individuals labeled as problematic or "at risk," it is imperative that interventions occur at all of these levels.

Institutions training professional and other service personnel also need to strengthen their focus on child development and relationship issues. This is particularly true of many helping professions, where it is still possible to receive credentials with either limited or no courses in applied child development or social and human behavior. The result is a pattern of punitive responses to and low expectations of children who show competencies in skills generally unrecognized or devalued. With better understanding of developmental needs and precipitating factors, training programs challenge preexisting beliefs and offer novel interpretations of expressed behaviors and strategies for addressing them. Improved personnel training, systems of accountability, and incentives should produce sensitive staff that are equipped to fulfill the special needs of minority youth and their families.

There should be increased recognition of early symptoms and access to academically supportive programs. Early intervention is critical to deter more complex problems that occur later. Issues of comorbidity, for example, are less prevalent and less resistant to treatment when identified early (Sameroff \& Seifer, 1995). African Americans continue to be ov- errepresented in special education programs where they are often misdiagnosed and incorrectly placed. Because those in low-income communities frequently receive minimal academic instruction and inadequate remedial services, their potential for educational development is diminished and their accumulated frustrations contribute to educational disengagement: a common factor among many youth with emotional and behavioral problems. Although the school context may not be the source of the problems, it could facilitate early intervention and deter exacerbating conditions.

Discontinuities across contexts force youth to navigate difficult environments and relationships, with access to few coping resources (see Phelan et al., 1991). Therefore, policies can focus on forging alliances between schools, churches, social and civic organizations and businesses. There is an increased likelihood of youth success when institutions systematically decrease the real and potential alienation between their own services, the youth being served, and youths' other salient social networks (Comer, 1989). Institutional relationships will make it possible for youth to experience the positive attachment, imitation, identification, and internalization of healthy attitudes and values that lead to optimal development. Generally, most school intervention projects have focused on improving the academic achievement and cognitive skills of children and not on overall sociocultural and emotional development throughout their years in school. On the other hand, most mental health programs focus on eliminating the problem behavior without a clear understanding of which sociocultural factors are most relevant and appropriate for some youth or how to maximize potential available resources and build competencies.

We must increase funding for the implementation of maintenance programs. New normative challenges, such as those associated with puberty, arise for all youth throughout development. As noted, factors such as structural racism and poverty exacerbate these normative developmental tasks for youth of color and low economic resource youth. Thus, sustained intervention is necessary throughout adolescence; merely providing programs in 
preschool or elementary school is not enough to facilitate resilient outcomes.

Reducing stressors and enhancing supports. Current models of practitioner training require alteration to increase substantive knowledge, to enhance knowledge of normal and abnormal development, and to facilitate skills needed to interact with children and parents from culturally different backgrounds.

Parental involvement is useful in identifying and intervening in behavior problems; however, there is a need for additional support. This is particularly true of parents with children in early adolescence. Therefore, incentives can be provided for institutions that provide services and facilitate relationships between other institutions in providing support to families. Supports for increasing parenting skills and resources should be made available through schools, community organizations, and churches since few resources are identifiable by poor, racial/ethnic parents although their hopes and aspirations mirror those of more economically advantaged groups. Low-income parents have fewer child-rearing resources than middle-income parents (Spencer \& Swanson, 2000), and thus require additional support (Solarz, 2001).

Either request or pay closer attention to interindividual variability in study and program outcomes. Consider the moderating effects of individual factors (i.e., gender or ethnicity) or contextual factors (i.e., neighborhood resources or school) and how they are defined.

Integrate diverse resources (home, school, businesses, and community) to reduce stress associated with an adolescent's transition between the home, school, and neighborhood environments.

\section{Conclusion}

Too often empirical investigations do not address the interactive effects of structural conditions, historical forces, psychological processes, and a priori assumptions of psychopathology. While some research addresses the complex issues necessary for understanding the multicausality and interindividual variability in the expression of behavioral problems, most re- main methodologically and conceptually unchallenged. We have attempted to illustrate how PVEST, in conjunction with competent methodological innovations, can be used as a conceptual model to analyze development and behavior.

Resources for overcoming formidable obstacles (i.e., poverty, crime-ridden environments) are available, but they are often difficult to locate and their significance underestimated. As a result of macroeconomic and technological developments in recent decades, it has become increasingly difficult for many youth to successfully navigate the varying obstacles. Outcomes associated with pathology may, after closer examination, be revealed as short-term adaptive strategies for coping with encountered stressors. The strategies used, however, become increasingly maladaptive over time as their usefulness, when employed in varied contexts, becomes unchallenged and less flexible. Policy development and implementation have become a mechanism for lessening the impact of poverty and untoward circumstances impacting child outcomes (Schorr, 1989, 1997).

Despite concerted efforts to impact the lives of children and youth, negative developmental outcomes continue to occur. Research and policy programs for diverse youth must be representative and sensitive to unavoidable maturation and experience-dependent developmental processes (e.g., social cognition), racial/ethnic identification, and contextual or structural conditions that produce environmental risks. Ignoring these factors will unavoidably create poor supports and inadequate social policies and serve to compromise the socioemotional development of many youth. To provide greater resource accessibility and longrange effectiveness, policies and programs must utilize diagnostic strategies that are sensitive to developmental and contextual influences in addition to similarly conceptualized studies. Consistent with a PVEST-based analysis, such an approach will contribute to comprehensive services that negate risk factors, customize necessary supports, minimize the stability of maladaptive coping strategies, foster productive identities, and promote greater resilience, as stage-specific coping outcomes, among all diverse youth. 


\section{References}

Ainsworth, M. D. S. (1979). Infant-mother attachment. American Psychologist, 34, 932-937.

Anthony, E. J. (1974). Introduction: The syndrome of the psychologically vulnerable child. In E. J. Anthony \& C. Koupernik (Eds.), The child in his family: Children at psychiatric risk (Vol. 3, pp. 3-10). New York: Wiley.

Bonilla-Silva, E. (1997). Rethinking racism: Toward a structural interpretation. American Sociological Review, 62, 465-480.

Bronfenbrenner, U. (1985). Summary. In M. B. Spencer, G. K. Brookins, \& W. R. Allen (Eds.), Beginnings: Social and affective development of Black children (pp. 67-73). New York: Erlbaum.

Bronfenbrenner, U. (1989). Ecological systems theory. In R. Vasta (Ed.), Annals of child development (pp. 187-248). Greenwich, CT: JAI Press.

Brooks-Gunn , J., Duncan, G., Klebanov, P., \& Sealand, N. (1993). Do neighborhoods influence child and adolescent development? American Journal of Sociology, 99, 353-395.

Brooks-Gunn, J. E., Duncan, G. J. E., \& Aber, J. L. E. (Eds.). (1997a). Neighborhood poverty: Context and consequences for children (Vol. I). New York: Russell Sage Foundation.

Brooks-Gunn, J. E., Duncan, G. J. E., \& Aber, J. L. E. (Eds.). (1997b). Neighborhood poverty: Policy implications in studying neighborhoods (Vol. II). New York: Russell Sage Foundation.

Burton, L., Price-Spratlen, T., \& Spencer, M. B. (1997). On ways of thinking about neighborhoods: Implications for studying context and developmental outcomes for children. In J. Brooks-Gunn, G. J. Duncan, \& J. L. Aber (Eds.), Neighborhood poverty: Policy implications in studying neighborhoods (Vol. II, pp. 132-144). New York: Russell Sage Foundation.

Capute, A. J., Shapiro, B. K., Palmer, F. B., Ross, A., \& Wachtel, R. C. (1985). Normal gross motor development: The influences of race, sex and socioeconomic status. Developmental Medicine and Child Neurology, 27, 635-643.

Cartographic Modeling Laboratory. (2001). NeighborhoodBase. University of Pennsylvania. Retrieved December 23, 2002 from http://cml.upenn.edu/nbase

Churchill, W. (1994). Indians are us? Culture and genocide in native North America. Monroe, ME: Common Courage Press.

Cicchetti, D., \& Aber, J. L. (Eds.). (1998). Contextualism and developmental psychopathology [Special Issue] Development and Psychopathology, 10(2).

Cicchetti, D., \& Carlson, V. (Eds.). (1989). Child maltreatment: Theory and research on the causes and consequences of child abuse and neglect. New York: Cambridge University Press.

Cole, M. (1996). Cultural psychology, A once and future discipline. Cambridge, MA: Belknap Press of Harvard University Press.

Comer, J. P. (1989). Child development and education. Journal of Negro Education, 58, 125-139.

Conley, D. (1999). Being Black, living in the red. Berkeley, CA: University of California Press.

Connell, J. P., Spencer, M. B., \& Aber, J. L. (1994). Educational risk and resilience in African American youth: Context, self, action and outcomes in school. Child Development, 65, 493-506.

Corrigan, P. W., \& Penn, D. L. (1999). Lessons from social psychology on discrediting psychiatric stigma. American Psychologist, 54, 765-776.

Coulton, C. J., Korbin, J., Chan, T., \& Su, M. (2001). Mapping residents' perceptions of neighborhood boundaries: A methodological note. American Journal of Community Psychology, 29, 371-383.

Cross, W. E. (1971, July). The Negro-to-Black conversion experience. Black World, 13-27.

Cross, W. E . (1991). Shades of Black: Diversity in African American identity. Philadelphia PA: Temple University Press.

Cunningham, M., \& Spencer, M. B. (2000). Conceptual and methodological issues in studying minority adolescents. In R. Montemayor, G. R. Adams, \& T. P. Gullotta (Eds.), Adolescent diversity in ethnic, economic and cultural contexts (pp. 235-257). Thousand Oaks, CA: Sage.

Dabrowski, I. (1983). Ecological determinants of "White ethnic" identity in St Louis, Missouri. Social Behavior and Personality, 11, 49-57.

Dannefer, D. (1992). On the conceptualization of context in developmental discourse. In D. L. Featherman, R. M. Featherman, \& M. Perlmutter (Eds.), Life-span development and behavior. Hillsdale, $\mathrm{NJ}$ : Erlbaum.

Day, J. C. (1996). Population projections of the United States by age, sex, race, and Hispanic origin: 1995 to 2050 (US Bureau of the Census, Current Population Reports, P25-1130). Washington, DC: US Government Printing Office.

Epstein, J., \& Botvin, G. (2000). Methods to decrease attrition in longitudinal studies with adolescents. Psychological Reports, 87, 139.

Erikson, E. (1969). Identity: Youth and crisis. New York: Norton.

Fisher, C. B., Jackson, J. F., \& Villarruel, F. A. (1998). The study of African American and Latin American children and youth. In W. Damon \& R. M. Lerner (Eds.), Handbook of child psychology: Vol. 1. Theoretical models of human development (pp. 11451207). New York: Wiley.

Fordham, S., \& Ogbu, J. U. (1986). Black students' school success: Coping with the "burden of acting White." Urban Review, 18, 176-206.

Fuligni, A. J. (1998). The adjustment of children from immigrant families. Current Directions in Psychological Science, 7, 99-103.

Fuligni, A. J., Tseng, V., \& Lam, M. (1999). Attitudes toward family obligations among American adolescents with Asian, Latin American, and European backgrounds. Child Development, 70, 1030-1044.

Garcia Coll, C., Akerman, A., \& Cicchetti, D. (2000). Cultural influences on developmental processes and outcomes: Implications for the study of development and psychopathology. Development and Psychopathology, 12, 333-356.

Garcia Coll, C., Lamberty, G., Jenkins, R., McAdoo, H. P., Crnic, K., Wasik, B. H., \& Garcia, H. V. (1996). An integrative model for the study of developmental competencies in minority children. Child Development, 67, 1891-1914.

Garcia Coll, C. T., \& Magnuson, K. (1999). Cultural influences on child development: Are we ready for a 
paradigm shift? In C. Nelson \& A. Masten (Eds.), Minnesota Symposium on Child Psychology (Vol. 29). Mahwah, NJ: Erlbaum.

Ge, X., Conger, R. D., \& Elder, G. H. (2001). Pubertal transition, stressful life events, and the emergence of gender differences in adolescent depressive symptoms. Developmental Psychology, 37, 404.

Gonzales, J. (2000). Harvest of empire: A history of Latinos in America. New York: Viking.

Greenberg, M. T., Domitrovich, C., \& Bumbarger, B. (2001). The prevention of mental disorders in schoolaged children: Current state of the field. Prevention \& Treatment, 4, Article 0001a. Retrieved December 7 , 2002 from http://journals.apa.org/prevention/volume4/ pre0040001a.html

Haney Lopez, I. F. (1996). White by law: The legal construction of race. New York: New York University Press.

Harpalani, V. (1999). Research on racial stereotyping. Developmental consequences and considerations. Unpublished manuscript, University of Pennsylvania.

Harpalani, V. (2001, April). Racial stereotyping and Black athletic achievement: Developmental and ethical considerations. Paper presented at the 2001 Biennial Meeting of the Society for Research in Child Development, Minneapolis, MN.

Harpalani, V. (2002). What does "acting White" really mean?: Racial identity formation and academic achievement among Black youth. Penn GSE Perspectives on Urban Education, 1, Article C0001. Retrieved December 7, 2002 from http://www.urbanedjournal.org/ commentaries/c0001.html

Harris, C. I. (1993). Whiteness as property. Harvard Law Review, 106, 1709-1795.

Harrison, A. O., Wilson, M. N., Pine, C. J., \& Chan, S. Q. (1990). Family ecologies of ethnic minority children. Child Development, 61, 347-362.

Hawkins, D. F. (2002). Devalued lives and racial stereotypes: Ideological barriers to the prevention of family violence among Blacks. In S. L. Gabbidon, H. T Greene, \& V. D. Young (Eds.), African American classics in criminology and criminal justice (pp. 199212). Thousand Oaks, CA: Sage.

Hawkins, J., Catalano, R., Kostermann, R., Abbott, R., \& Hill, K. (1999). Preventing adolescent health risk behaviors by strengthening protection during childhood. Archives of Pediatrics and Adolescent Medicine, 153, 226.

Helms, J. E. (Ed). (1990). Black and White racial identity: Theory, research, and practice. New York: Greenwood Press.

Herring, C. (Ed.). (1997). African Americans and the public agenda: The paradoxes of public policy. Thousand Oaks, CA: Sage.

Hibbs, E. D., \& Krener, P. (1996). Ethical issues in psychosocial treatment research with children and adolescents. In K. Hoagwood, P. S. Jensen, \& C. B Fisher (Eds.), Ethical issues in mental health research with children and adolescents (pp. 59-71). Mahwah, NJ: Erlbaum.

Hillier, A. (1999). Neighborhoods or con-census tracts? Philadelphia, PA: University of Pennsylvania.

Huckfeldt, R. (1983). Social contexts, social networks, and urban neighborhoods: Environmental constraints on friendship choice. American Journal of Sociology, $89,651-669$.

Ingold, T. (1994). Introduction to culture. In T. Ingold (Ed.), Companion encyclopedia of anthropology: $\mathrm{Hu}$ manity, culture and social life (pp. 329-349). London: Routledge.

Joe, S., \& Kaplan, M. S. (2002). Firearm-related suicide among young African American males. Psychiatric Services, 53, 332-334.

Kardiner, A., \& Ovesey, L. (1951). The mark of oppression. Cleveland, $\mathrm{OH}$ : World Publishing.

Lamdin, D. J. (1996). Evidence of student attendance as an independent variable education production function. Journal of Educational Research, 89, 155-162.

Lee, C. D., Spencer, M. B., \& Harpalani, V. (in press). Every shut eye ain't sleep: Studying how people live culturally. Educational Researcher.

Luster , T., \& Okagaki, L. (1993). Multiple influences in parenting: Ecological and life-course perspectives. In T. Luster \& L. Okagaki (Eds.), Parenting: An ecological perspective. Hillsdale, NJ: Erlbaum.

Luthar, S. S., \& Becker, B. E. (2002). Privileged but pressured? A study of affluent youth. Child Development, 73, 1593-1610.

Luthar, S. S., \& Cicchetti, D. (2000). The construction of resilience: Implications for interventions and social policies. Development and Psychopathology, 12, 857885.

Luthar, S. S., Cicchetti, D., \& Becker, B. (2000). The construct of resilience: A critical evaluation and guidelines for future work. Child Development, 71, 543562.

Luthar, S. S., \& Latendresse, S. J. (2002). Adolescent risk: The cost of affluence. New Directions for Youth Development, 95, 101-121.

Luthar, S. S., \& McMahon, T. J. (1996). Peer reputation among inner-city adolescents: Structure and correlates. Journal of Research on Adolescence, 6, 581-603.

Lynch, M., \& Cicchetti, D. (1998). An ecological-transactional analysis of children and contexts: The longitudinal interplay among child maltreatment, community violence, and children's symptomatology. Development and Psychopathology, 10, 235-257.

Manski, C. (1993). Identification of endogenous social effects: The reflection problem. Review of Economic Studies, 60, 531-542.

Marcia, J. E. (1966). Development and validation of egoidentity status. Journal of Personality and Social Psychology, 3, 551-558.

Mayer, S. E., \& Jencks, C. (1989). Growing up in poor neighborhoods: How much does it matter? Science, $243,1441-1445$.

McAdoo, J. L. (1988). Changing perspectives on the role of the Black father. In P. Bronstein \& C. P. Cowan (Eds.), Fatherhood today: Men's changing role in the family (pp. 79-94). New York: Wiley.

McAdoo, J. L. (1993). The roles of African American fathers: An ecological perspective. Families-in-Society, 74, 28-35.

McIntosh, P. (1989, July/August). White privilege: Unpacking the invisible knapsack. Peace and Freedom, $10-12$.

McMullin, R. (1975.) The neighborhoods of Philadelphia. Philadelphia, PA: Philadelphia Office of the Deputy Managing Director for Housing.

New Orleans Public Schools. Department of Educational Accountability. (1994). Districtwide norm-referenced and criterion-referenced tests results, 1993: An exploratory data analysis of the relationship between achievement and absenteeism in New Orleans Public Schools (ERIC Document Reproduction Service No. ED369819). New Orleans, LA: Author. 
Ogbu, J. U. (1978). Minority education and caste: The American system in cross-cultural perspective. New York: Academic Press.

Ogbu, J. U. (1985). A cultural ecology of competence among inner-city Blacks. In M. B. Spencer, G. K. Brookins, \& W. R. Allen (Eds.), Beginnings: The social and affective development of Black children (pp. 45-66). Hillsdale, NJ: Erlbaum.

Ogbu, J. U. (1990). Minority education in a comparative perspective. Journal of Negro Education, 59, 45-56.

Parker, S., Nichter, M., Nichter, M., Vuckovic, N., Sims, C., \& Ritenbaugh, C. (1995). Body image and weight concerns among African American and White adolescent females: Differences that make a difference. $\mathrm{Hu}$ man Organization, 54, 103-113.

Perry, B. D., Pollard, R. A., Blakley, T. L., Baker, W. L., \& Vigilante, D. (1995). Childhood trauma, the neurobiology of adaptation, and "use-dependent" development of the brain: How "states" become "traits." Infant Mental Health Journal, 16, 271-291.

Perry, P. (2001). White means never having to say you're ethnic: White youth and the construction of "cultureless" identity. Journal of Contemporary Ethnography, 30, 56-91.

Peshkin, A. (2000). The nature of interpretation in qualitative research. Educational Researcher, 29, 5-9.

Phelan, P., Davidson, A. L., \& Cao, H. T. (1991). Students' multiple worlds: Negotiating the boundaries of family, peer, and school cultures. Anthropology \& Education Quarterly, 22, 224-250.

Phinney, J. (1990). Ethnic identity in adolescents and adults: Review of research. Psychological Bulletin, 108, 499-514.

Phinney, J. (1992). The Multigroup Ethnic Identity Measure: A new scale for use with adolescents and young adults from diverse groups. Journal of Adolescent Research, 7, 156-176.

Pollak, S. D., Cicchetti, D. \& Klorman, R. (1998). Stress, memory and emotion: Developmental considerations from the study of child maltreatment. Development and Psychopathology, 10, 811-828.

Posner, D. (2000, October 20-22). Measuring ethnic identities and attitudes regarding inter-group relations: Methodological pitfalls and a new technique. Unpublished manuscript, University of Pennsylvania.

Prashad, V. (2000). The karma of Brown folk. Minneapolis: University of Minnesota Press.

Richters, J. E., \& Cicchetti, D. (1993). Mark Twain meets $D S M-I I I-R$. Conduct disorder, development, and the concept of harmful dysfunction. Development and Psychopathology, 5, 5-29.

Rowe, W., Bennett, S. K., \& Atkinson, D. R. (1994). White racial identity models: A critique and alternative proposal. Counseling Psychologist, 22, 129-146.

Sameroff, A. J. \& Seifer, R. (1995). Accumulation of environmental risk and child mental health. In $\mathrm{H}$. E. Fitzgerald \& B. M Lester (Eds.), Children of poverty: Research, health, and policy issues (pp. 233-258). New York: Garland.

Sampson, R. J., \& Morenoff, J. D. (1997). Ecological perspectives on the neighborhood context of poverty: Past and present. In J. Brooks-Gunn, G. J. Duncan, \& J. L. Abers (Eds.), Neighborhood poverty: Policy implications in studying neighborhoods (Vol. II, pp. 122). New York: Russell Sage Foundation.

Sawyer, T. (1997, August). Measuring race and ethnicity: Meeting public policy goals. Paper presented at the annual meeting of the American Statistical Asso- ciation. Retrieved February 3, 2002 from http://www .amstat.org/publications/tas/abstracts_98/sawyer.html. Schorr, L. B. (1989). Within our reach: Breaking the cycle of disadvantage. New York: Anchor Books Doubleday.

Schorr, L. B. (1997). Common purpose: Strengthening families and neighborhoods to rebuild America. New York : Anchor Books Doubleday.

Shakoor, B. H., \& Chalmers, D. (1991). Co-victimization of African American children who witness violence: Effects on cognitive, emotional, and behavioral development. Journal of the National Medical Association, $83,233-239$.

Sikes, G. (1998). 8 Ball chicks: A year in the violent world of girl gangsters. New York: Doubleday.

Solarz, A. L. (2001). Investing in children, families, and communities: Challenges for an interdivisional public policy collaboration. American Journal of Community Psychology, 29, 1-14.

Spencer, M. B. (1982). Personal and group identity of Black children: An alternative synthesis. Genetic Psychology Monographs, 103, 59-84.

Spencer, M. B. (1985). Cultural cognition and social cognition as identity correlates of Black children's personal-social development. In M. B. Spencer, G. K. Brookins, \& W. Allen (Eds.), Beginnings: The social and affective development of Black children (pp. 215230). Hillsdale, NJ: Erlbaum.

Spencer, M. B. (1995). Old issues and new theorizing about African American Youth: A phenomenological variant of ecological systems theory. In R. L. Taylor (Ed.), Black youth: Perspectives on their status in the United States (pp. 37-70). Westport, CT: Praeger.

Spencer, M. B. (1999a). Social and cultural influences on school adjustment: The application of an identityfocused cultural ecological perspective. Educational Psychologist, 34, 43-57.

Spencer, M. B. (2001). Resiliency and fragility factors associated with the contextual experiences of low resource urban African American male youth and families. In A. Booth \& A. C. Crouter (Eds.), Does it take a village? Community effects in children, adolescents and families (pp. 51-77). Mahwah, NJ: Erlbaum.

Spencer, M. B., Cole, S. P., DuPree, D., Glymph, A., \& Pierre, P. (1993). Self-efficacy among urban African American early adolescents: Exploring issues of risk, vulnerability, and resilience. Development and Psychopathology, 5, 719-739.

Spencer, M. B., Cross, W. E., Harpalani, V., \& Goss, T. N. (in press). Historical and developmental perspectives on Black academic achievement: Debunking the "acting White" myth and posing new directions for research. In C. C. Yeakey (Ed.), Surmounting all odds: Education, opportunity, and society in the new millennium. Greenwich, CT: Information Age Publishers.

Spencer, M. B., \& Cunningham, M. (in press). Patterns of resilience and vulnerability: Examining diversity within African American youth. In G. K. Brookins \& M. S. Spencer (Eds.), Ethnicity and diversity: Minorities no more. Hillsdale, NJ: Erlbaum.

Spencer, M. B., Cunningham, M., \& Swanson, D. P. (1995). Identity as coping: Adolescent African American males' adaptive responses to high risk environments. In H. W. Harris, H. C. Blue, \& E. H. Griffith (Eds.), Racial and ethnic identity (pp. 31-52). New York: Routledge.

Spencer, M. B. \& Dornbusch, S. (1990). American mi- 
nority adolescents. In S. Feldman \& G. Elliot (Eds.), At the threshold: The developing adolescent (pp. 123146). Cambridge, MA: Harvard University Press.

Spencer, M. B., Dupree, D., Cunningham, M., Harpalani, V., \& Munoz-Miller, M. (2003). Vulnerability to violence: A contextually-sensitive, developmental perspective on African American adolescents. Journal of Social Issues, 59, 33-49.

Spencer, M. B., Dupree, D., \& Hartmann, T. (1997). A phenomenological variant of ecological systems theory (PVEST): A self-organization perspective in context. Development and Psychopathology, 9, 817-833.

Spencer, M. B., \& Harpalani, V. (2001). African American adolescents, Research on. In R. M. Lerner \& J. V. Lerner (Eds.), Today's teenager: Adolescents in America (pp. 30-32). Denver, CO: ABC-CLIO.

Spencer, M. B., \& Harpalani, V. (in press). Nature, nurture, and the question of how? A phenomenological variant of ecological systems theory (PVEST). In C. Garcia Coll, E. L. Bearer, \& R. M. Lerner (Eds.), $\mathrm{Na}$ ture and nurture: The complex interplay of genetic and environmental influences on human behavior and development. Mahwah, NJ: Erlbaum.

Spencer, M. B., \& Horowitz, F. D. (1973). Racial attitudes and color concept-attitude modification in Black and Caucasian preschool children. Developmental Psychology, 9, 246-254.

Spencer, M. B., \& Markstrom-Adams, C. (1990). Identity processes among racial and ethnic minority children in America. Child Development, 61, 290-310.

Spencer, M. B., McDermott, P. A., Burton, L. M., \& Kochman, T. J. (1997). An alternative approach to assessing neighborhood effects on early adolescent achievement and problem behaviors. In J. BrooksGunn, G. J. Duncan, \& J. L. Aber (Eds.), Neighborhood poverty: Policy implications in studying neighborhoods (Vol. II, pp. 145-163). New York: Russell Sage Foundation.

Spencer, M. B., Noll, E., Stoltzfus, J., \& Harpalani, V. (2001). Identity and school adjustment: Revisiting the "acting White" assumption. Educational Psychologist, 36, 21-30.

Spencer, M. B., Silver, L. J., Seaton, G., Tucker, S. R., Cunningham, M., \& Harpalani, V. (2001). Race and gender influences on teen parenting: An identityfocused cultural-ecological perspective. In T. Urdan \& F. Pajares (Eds.), Adolescence and education ( $\mathrm{Vol}$
1, pp. 231-268). Greenwich, CT: Information Age Publishers.

Spencer, M. B. \& Swanson, D. P. (2000). The role of families in promoting good youth outcomes. In S. Danziger \& J. Waldfogel (Eds.), Securing the future: Investing in children from birth to college (pp. 182204). New York: Sage.

Sroufe, L. A., Carlson, E. A, Levy, A. K., \& Egeland, B. (1999). Implications of attachment theory for developmental psychopathology. Development and Psychopathology, 11, 1-13.

Stevenson, H. C. (1997). Missed, dissed, and pissed: Making meaning of neighborhood risk, fear and anger management in urban Black youth. Cultural Diversity and Mental Health, 3, 37-52.

Swanson, D. P., \& Spencer, M. S. (1991). Youth policy, poverty, and African Americans: Implications for resilience. Education and Urban Society, 24, 148-161.

Swanson, D. P., \& Spencer, M. B. (1998). Developmental and cultural context considerations for research on African American adolescents. In H. E. Fitzgerald, B. M. Lester \& B. Zuckerman (Eds.), Children of color: Research, health, and public policy issues (pp. 53-72) Chicago: University of Chicago Press.

Swanson, D. P., Spencer, M. B., \& Petersen, A. (1998). Adolescent identity formation: 21 st century issues and opportunities. In K. M. Borman \& B. Schneider (Eds.), Youth experiences and development: Social influences and educational challenges. Chicago: University of Chicago Press.

Takaki, R. (1998). Strangers from a different shore: A history of Asian Americans. New York: Little, Brown.

Trickett, P. K., \& McBride-Chang, C. (1995). The developmental impact of different forms of child abuse and neglect. Developmental Review, 15, 311-337.

Tylor, E. B. (1958). Primitive culture. New York: Harper \& Row. (Original work published 1871)

US Department of Justice, Office of Juvenile Justice and Delinquency Prevention. (2001, September). Truancy reduction: Keeping students in school. Juvenile Justice Bulletin, 1-15.

Van Oers, B. (1998). From context to contextualizing. Learning and Instruction, 8, 473-488.

Yancey, A. K., Aneshensel, C. S., \& Driscoll, A. K. (2001). The assessment of ethnic identity in a diverse urban youth population. Journal of Black Psychology, 27, 190-208. 